\title{
Final Report COVER PAGE
}

Federal Agency to which Report is submitted: DOE EERE - Wind \& Water Power Program

Recipient: Univ of Missouri System - Missouri S\&T

Award Number: DE-EE0004569

Project Title: Remote Monitoring of the Structural Health of Hydrokinetic Composite Turbine Blades

Project Period: Sept. 2010 to Mar. 2011

Principle Investigator: Joshua L. Rovey, roveyi@mst.edu, 573-341-4613

Report Submitted by:

Date of Report: Sept. 21, 2012

Covering Period: Oct. 2010 to May 2012

Working Partners:

Cost-Sharing Partners: [

DOE Project Team: DOE HQ Program Manager - Jose Zayas

DOE Field Contract Officer - Pamela Brodie

DOE Field Grants Management Specialist - XXXX

DOE Field Project Officer - XXXX

DOE/CNJV Project Monitor - XXXX

Signature of Submitting Official:

(electronic signature is acceptable) 
Acknowledgment: This report is based upon work supported by the U. S. Department of Energy under Award No. DE-EE0004569.

Disclaimer: Any findings, opinions, and conclusions or recommendations expressed in this report are those of the author(s) and do not necessarily reflect the views of the Department of Energy

Proprietary Data Notice: If there is any patentable material or protected data in the report, the recipient, consistent with the data protection provisions of the award, must mark the appropriate block in Section K of the DOE F 241.3, clearly specify it here, and identify them on appropriate pages of the report. Other than patentable material or protected data, reports must not contain any proprietary data (limited rights data), classified information, information subject to export control classification, or other information not subject to release. Protected data is specific technical data, first produced in the performance of the award, which is protected from public release for a period of time by the terms of the award agreement. Reports delivered without such notice may be deemed to have been furnished with unlimited rights, and the Government assumes no liability for the disclosure, reproduction or use of such reports. 


\section{Table of Contents}

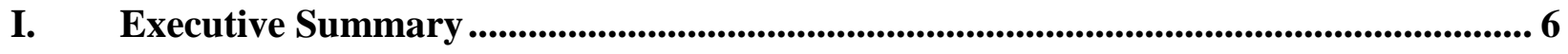

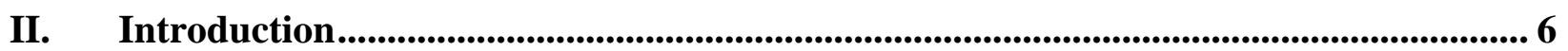

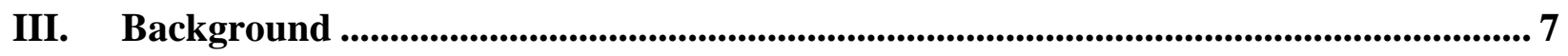

A. Hydrokinetic Energy Systems .................................................................... 8

B. Motivation - The Need for Composite Blades and Structural Health Monitoring .......... 9

1. Over Time, Fatigue Causes Failure ...................................................................... 10

2. Transient Events Lead to Damage and Failure ..................................................... 10

3. Remote Monitoring is Crucial........................................................................ 11

4. Lower Operation \& Maintenance Costs Enhance Investment Returns........................ 11

C. State of the Art of Remote Structural Health Monitoring ......................................... 12

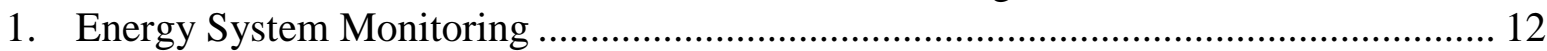

2. Structural Health Monitoring ............................................................................ 13

D. Original Component TRL Self-categorization - Was at TRL 1 ............................... 13

E. Plan to Advance Component to TRL 3 ................................................................. 14

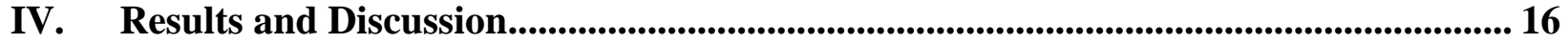

A. Structure \& Monitoring Sensor Development ......................................................... 16

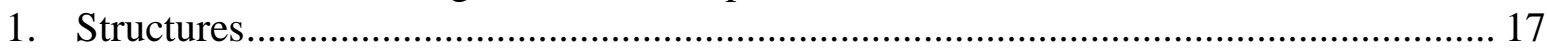

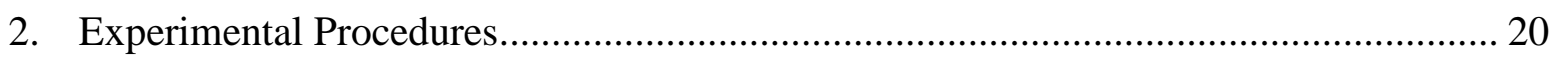

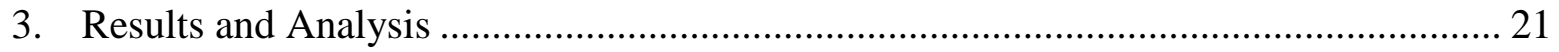

B. Acoustic Communication and Broadcasting Development ........................................ 23

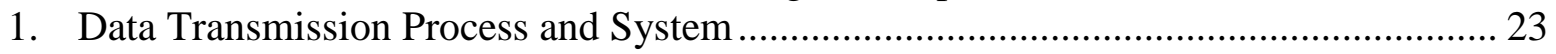

2. Results and Discussion............................................................................... 31

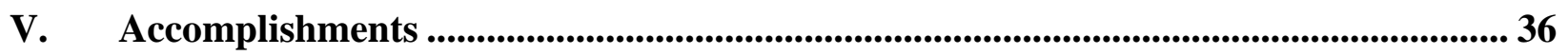

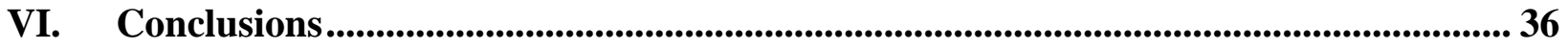

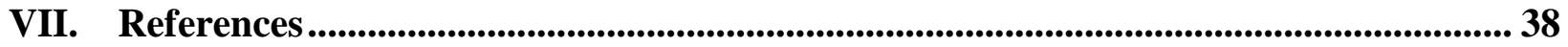




\section{List of Figures}

Figure 1: Hydrokinetic turbine blade structural health monitoring component. ......................... 7

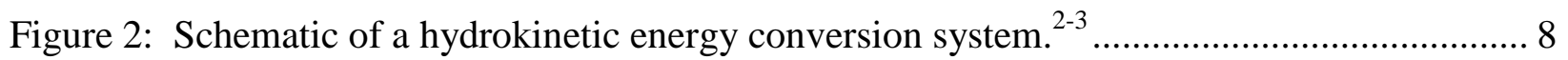

Figure 3: Hydrokinetic generator designs - a) Pelamis ${ }^{4,7}$ and b) Power buoy ${ }^{4,8}$ are both designed for wave energy; c) Oscillating water column ${ }^{4,9}$ is designed for near-shore tides; d) Axial flow turbine $^{4}$ and e) Ducted turbine ${ }^{4,10}$ are both designed for submerged current............................... 9

Figure 4: Hypothetical zone of potential damaging strike associated with a submerged free-flow turbine. ${ }^{14}$ 11

Figure 5 Composite Blade. 18

Figure 6: Strain Distribution of the Composite Beam along the Beam Length (x Direction) for Support on the Left End. 19

Figure 7: Strain Distribution of the Composite Blade along the Blade Length (x Direction) for Support on the Left End 19

Figure 8: Strain Gage Active Area. The FE Model Calculates Strain at Locations A, B, and C. 20

Figure 9: Experimental Setup for Static Strain Test (dimensions in cm) ............................... 20

Figure 10: Carbon/Epoxy Composite Beam with Sensor Layout (dimensions in cm)............... 21

Figure 11: Carbon/Epoxy Composite Blade with Sensor Layout (dimensions in cm)............... 21

Figure 12: Free-Vibration Strain Transient for the Eight-Layer Composite Beam ................... 22

Figure 13: Schematic of main components of the underwater acoustic communication system. 24

Figure 14. Transmitter Circuit 25

Figure 15: Receiver Circuit. 25

Figure 16: Attenuation and transmission rate of transmitter circuit vs. frequency in sea-water $\left(22^{\circ} \mathrm{C}\right)$ at depths of $1 \mathrm{~m}$. 27

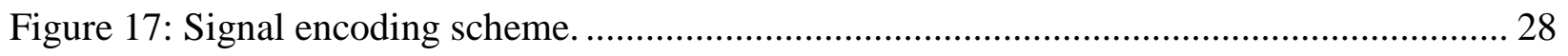

Figure 18: Transmitted ' 1 ' bit (solid box) and the following echo (dashed box)...................... 29

Figure 19: Bench top setup for communication validation and power consumption investigation.

Figure 20: Water Tunnel Test Section with (1) Receiver Transducer, (2) Transmitting Transducer, and (3) Power and Electronics Module. 31 
Figure 21: Constant and square wave simulated structural health data transmitted to the remote

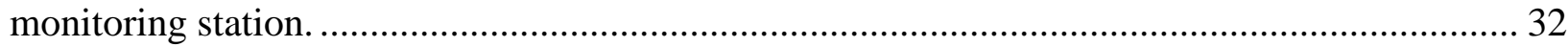

Figure 22: Half-cycle sine wave simulated structural health data transmitted to the remote

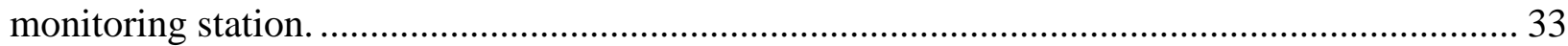

Figure 23: Time averaged current draw of the transmitter circuit vs. duty cycle....................... 34

Figure 24: Predicted transmitter circuit operating time vs. duty cycle for different battery

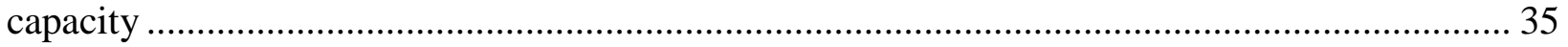




\section{Executive Summary}

A health monitoring approach is investigated for hydrokinetic turbine blade applications. Inservice monitoring is critical due to the difficult environment for blade inspection and the cost of inspection downtime. Composite blade designs have advantages that include long life in marine environments and great control over mechanical properties. Experimental strain characteristics are determined for static loads and free-vibration loads. These experiments are designed to simulate the dynamic characteristics of hydrokinetic turbine blades. Carbon/epoxy symmetric composite laminates are manufactured using an autoclave process. Four-layer composite beams, eight-layer composite beams, and two-dimensional eight-layer composite blades are instrumented for strain. Experimental results for strain measurements from electrical resistance gages are validated with theoretical characteristics obtained from in-house finite-element analysis for all sample cases. These preliminary tests on the composite samples show good correlation between experimental and finite-element strain results. A health monitoring system is proposed in which damage to a composite structure, e.g. delamination and fiber breakage, causes changes in the strain signature behavior. The system is based on embedded strain sensors and embedded motes in which strain information is demodulated for wireless transmission.

In-service monitoring is critical due to the difficult environment for blade inspection and the cost of inspection downtime. Composite blade designs provide a medium for embedding sensors into the blades for in-situ health monitoring. The major challenge with in-situ health monitoring is transmission of sensor signals from the remote rotating reference frame of the blade to the system monitoring station. In the presented work, a novel system for relaying in-situ blade health measurements in hydrokinetic systems is described and demonstrated. An ultrasonic communication system is used to transmit sensor data underwater from the rotating frame of the blade to a fixed relay station. Data are then broadcast via radio waves to a remote monitoring station. Results indicate that the assembled system can transmit simulated sensor data with an accuracy of $\pm 5 \%$ at a maximum sampling rate of 500 samples/sec. A power investigation of the transmitter within the blade shows that continuous max-sampling operation is only possible for short durations ( days), and is limited due to the capacity of the battery power source. However, intermittent sampling, with long periods between samples, allows for the system to last for very long durations ( years). Finally, because the data transmission system can operate at a high sampling rate for short durations or at a lower sampling rate/higher duty cycle for long durations, it is well-suited for short-term prototype and environmental testing, as well as long-term commercially-deployed hydrokinetic machines.

\section{Introduction}

The concept is a composite turbine blade for hydrokinetic energy systems that is capable of acquiring and transmitting information about its structural health. A schematic of the component concept is shown in Figure 1. The hydrokinetic energy system using a free flow turbine is placed underwater. Composite turbine blades, embedded with a fiber optic strain gage and acoustic transducer, are attached to the turbine and used to generate electricity in a remote location like the Wilds of Alaska. The fiber optic strain gage senses the degradation of the blade structure over time due to cyclic loading (fatigue) and transient environmental factors. A power and electronics module inside the blade conditions the fiber optic strain gage signal into an acoustic signal that is transmitted by the acoustic transducer. The acoustic waves propagate through the 
water to a receiver that is located near the shore or on the system foundation. The received acoustic signal can then be broadcast above water long distances by radio waves to the monitoring station. The broadcast signal can be interpreted at the monitoring station, yielding real-time strain data from the blade.

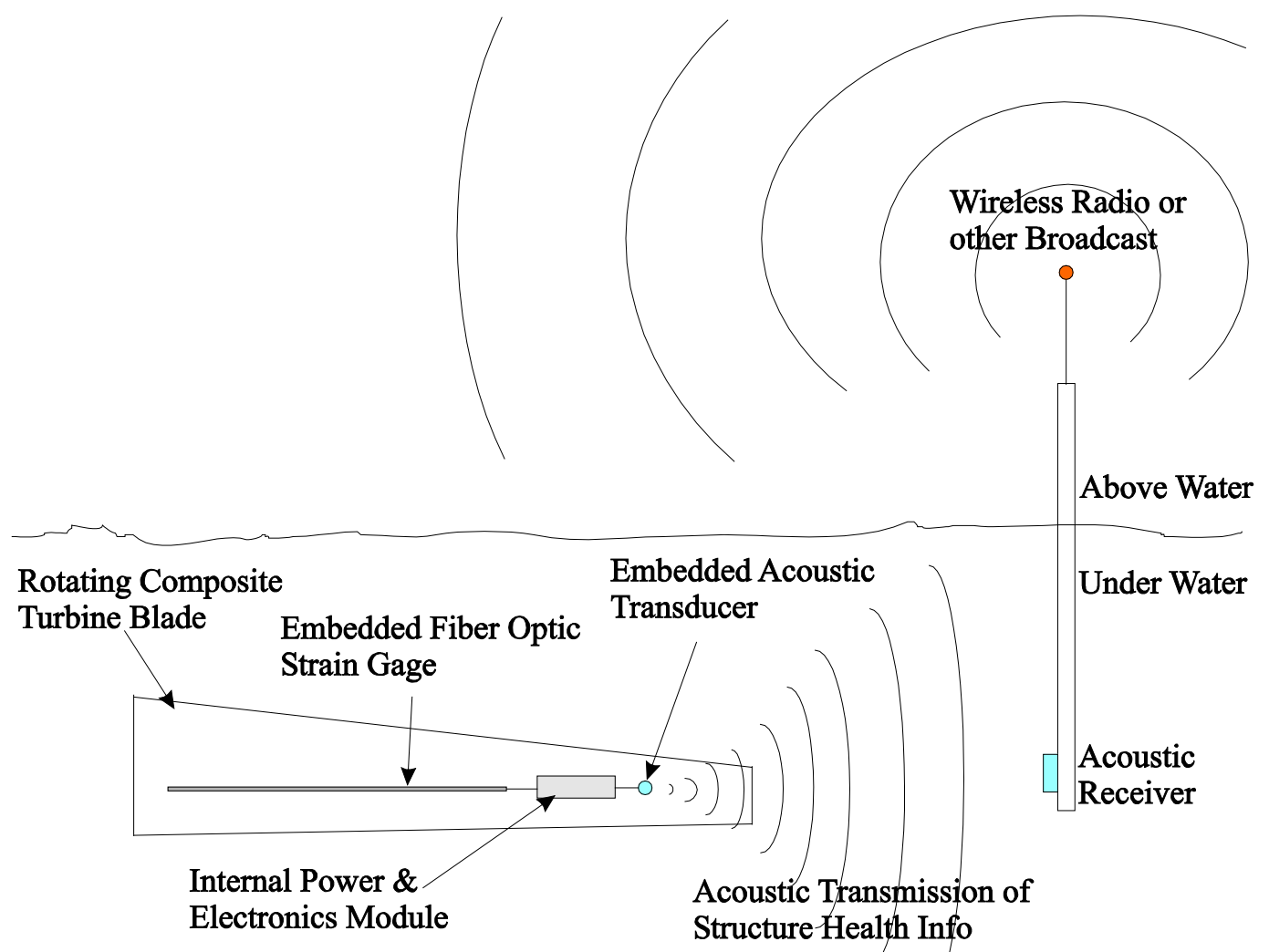

Figure 1: Hydrokinetic turbine blade structural health monitoring component.

The concept advances the state-of-the-art in two main areas. First, the turbine blade will be a composite structure instead of metal, which is used in state-of-the-art devices. Composite materials are durable, lightweight, and corrosion resistant. Metal structures are heavy and corrode easily, especially in sea or saltwater. Further, composite materials can be manufactured to contain embedded sensors so the health of the in-service structure can be monitored. Second, to transmit strain gage data, acoustic communication is used from the blade to the receiver station. The state-of-the-art uses radio wave communication from the blade to the receiver. In the aquatic environment required for hydrokinetic systems, radio communication is only possible for short distances $(<1 \mathrm{~m})$, at very low frequencies $(30-300 \mathrm{~Hz})$, with large antennae, and high transmission power. ${ }^{1}$ Acoustic communication is better suited for underwater applications.

\section{Background}

The energy in flowing river streams, tidal currents, and waves is being investigated as a potential source of renewable energy. Systems are being designed and developed to harness this 
hydrokinetic energy and convert it into electricity or other useful forms. A number of resource quantization and demonstrations have been conducted throughout the world and it is believed that both in-land water resources and the offshore ocean energy sector will benefit from this technology. The following section provides an overview of hydrokinetic energy systems. Then the need for a remote structural health monitoring component for these systems is described, followed by a description of the state-of-the-art in remote structural health monitoring.

\section{A. Hydrokinetic Energy Systems}

Hydrokinetic energy systems are designed to convert kinetic energy of a fluid (e.g., river or tidal current, waves) into electricity. They are generally classified in two broad categories: (a) wave energy conversion devices and (b) rotating devices. Wave energy conversion devices create a system of reacting forces in which two or more bodies move relative to each other while at least one body interacts with the waves. Rotating devices are deployed within a stream or current capturing kinetic energy from flowing water via a turbine that powers a generator.

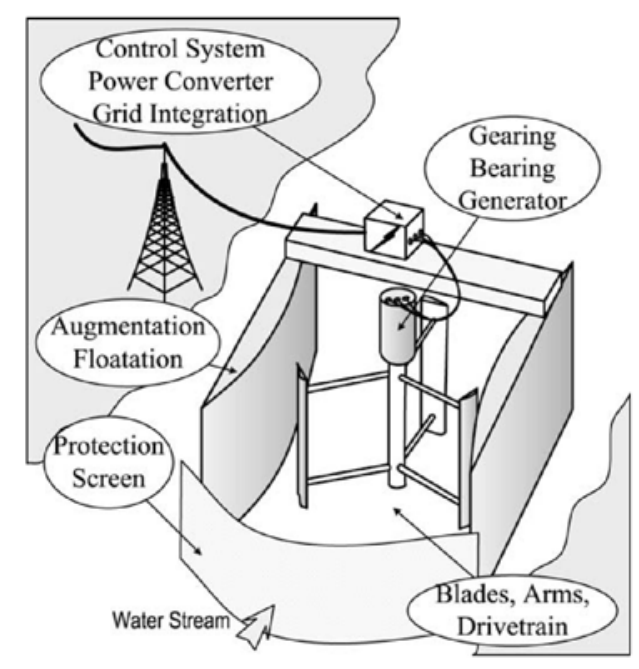

Figure 2: Schematic of a hydrokinetic energy conversion system. ${ }^{2-3}$

A schematic of a typical rotating device is shown in Figure $2 .^{2-3}$ The river or tidal current passes through a protection screen and into the turbine channel. In this particular case, the hydrokinetic system uses channel augmentation to concentrate the flow of the fluid around the turbine, permitting higher levels of energy extraction. The channel augmentation also serves as a floatation device for the system. Kinetic energy of the fluid causes the turbine to rotate and this rotational energy is extracted by the generator attached at the top of the turbine. Power from the hydrokinetic turbine is then coupled to the electrical grid through a power converter.

Hydrokinetic technology is still relatively immature and these systems have yet to see widespread use. However, there are at least three methods for harvesting hydrokinetic energy that have achieved some commercial success. ${ }^{4}$ Devices that have been constructed to utilize these different harvesting methods are shown in Figure 3. The pelamis and power buoy harvest ocean wave energy, while the oscillating water column operates near the shore to harvest energy from rising and falling tides. Each of these devices is designed for ocean operation. The axial 
flow turbine, which can be ducted or un-ducted, is designed to harvest energy from currents. These systems can be employed in both oceans and in-land rivers.

The number of licensing permits for hydrokinetic energy technology projects continues to increase and significant gains in market value are predicted in the near future. In early 2008, the FERC had 88 pending and issued permits for hydrokinetic energy systems. As of April 2010, this numbers have risen to 130 preliminary permits for hydrokinetic energy systems, with another 40 currently pending. ${ }^{5}$ In two years, the number of pending and issued permits has doubled. This increasing trend agrees with a 2009 market analysis by Pike Research that predicts the marine and hydrokinetic energy market value to grow considerably over the next 5 years. Specifically, at the end of 2008, the total installed capacity of marine and hydrokinetic systems was only 10 MW. By 2015, market predictions based on planned projects and installations suggest that between 2.7 to $10 \mathrm{GW}$ of installed power will be available, representing a market value between $\$ 6$ to $\$ 20$ billion. ${ }^{6}$ With this much potential gain, there is much interest in the continued development of hydrokinetic energy systems.
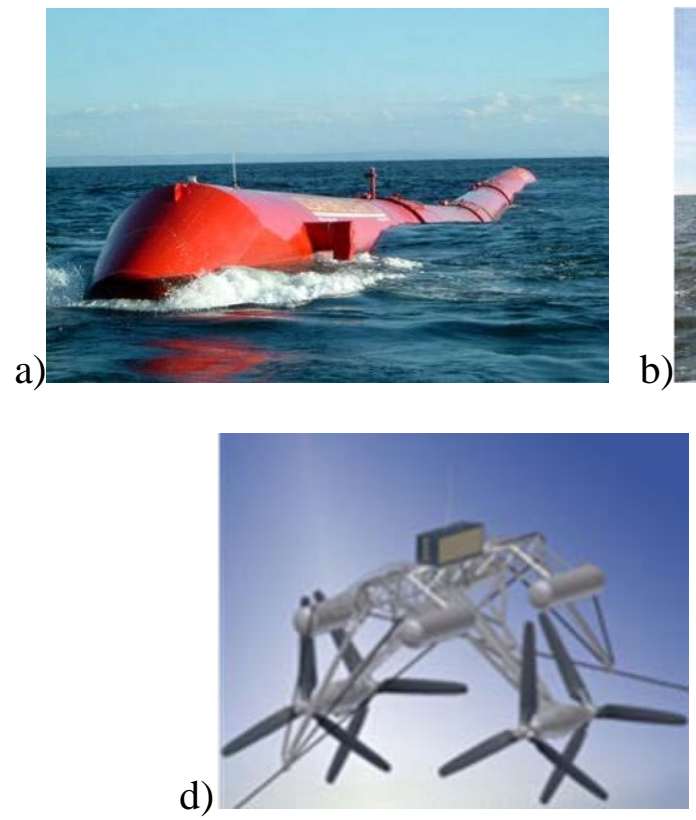

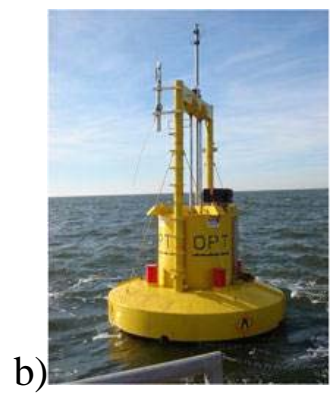

c)

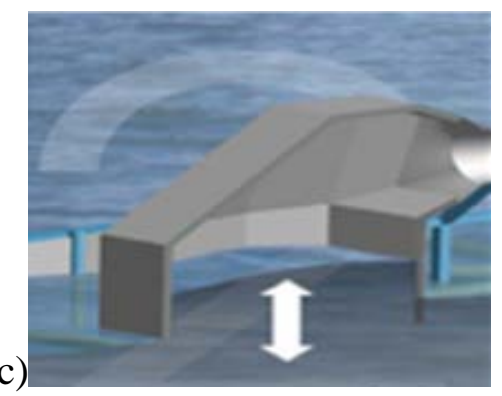

e)

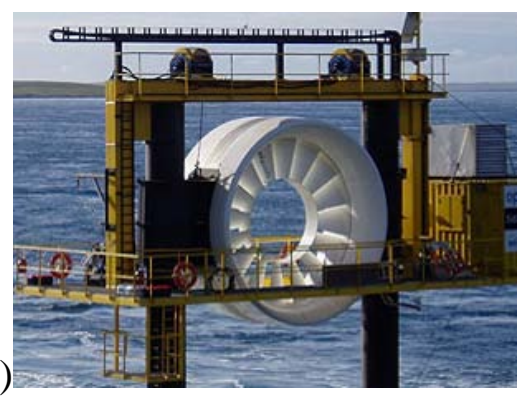

Figure 3: Hydrokinetic generator designs - a) Pelamis ${ }^{4,7}$ and b) Power buoy ${ }^{4,8}$ are both designed for wave energy; c) Oscillating water column ${ }^{4,9}$ is designed for near-shore tides; d) Axial flow turbine ${ }^{4}$ and e) Ducted turbine ${ }^{4,10}$ are both designed for submerged current.

\section{B. Motivation - The Need for Composite Blades and Structural Health Monitoring}

Composite turbine blades are better suited for hydrokinetic energy systems than state-of-the-art metallic blades. Composite blades are durable, lightweight, and corrosion resistant, which means they require minimal maintenance. Further, because they are lightweight they are able to rotate faster, increasing the efficiency of energy harvesting. In contrast, metal blades are heavy and corrode easily, especially in sea or saltwater where they are planned to be deployed. Metal blades are also unable to contain sensors that allow the structural health of the blade to be 
monitored. We are developing a new class of materials with embedded sensors so that the inservice structure health can be monitored.

The structural health of hydrokinetic energy systems needs to be monitored and it must be monitored remotely. This type of capability is important because the integrity of the structure is paramount for system operation and these systems are almost always located in areas difficult to access. The turbine blade is the critical structural component for energy extraction and it also bears the most dynamic load. Therefore, the proposed project plans to demonstrate remote monitoring of the structural health of a composite turbine blade for a hydrokinetic energy system.

The structural health of the turbine blade in a hydrokinetic energy system needs to be monitored. Fatigue and environmental effects both lead to structural degradation over the life of the blade. The natural cyclic loading of the blade over its lifetime leads slow degradation (fatigue). Impact damage due to environmental factors (e.g., marine life, vegetation, pollution) also decreases the structural integrity of the blade. Monitoring the structural health of the blade can lead to timely replacement of parts, notification of damage, and enhanced operational lifetime. All of which result in lower operation and maintenance costs and a higher return on investment.

\section{Over Time, Fatigue Causes Failure}

Fatigue causes degradation of structures and eventually leads to structure failure. Fatigue is due to continuous and cyclic loading of a structure. Over time, small cracks develop and propagate, reducing the structure integrity, and eventually cause it to break and fail. The onset and progression of this process leading to failure begins in regions with the highest structural strain. In many cases, however, regions with initial signs of fatigue (e.g., cracks) can be removed and replaced with reinforcing material through a process known as composite patching. With the current state-of-the-art metal blades, patching is not possible and degradation due to fatigue cannot be removed or reinforced. Patching is possible with composite turbine blades.

The proposed technology will make monitoring a composite structure to determine when it is fatigued and requires patching a much easier and less expensive process. Currently only off-line monitoring is available to determine the structural health of a composite component. This means that the structure must be removed from service and evaluated using traditional non-destructive test and evaluation techniques to determine if patching is necessary. With the proposed technology, the structural health of a composite turbine blade in a hydrokinetic energy system can be monitored while it is in service. In other words, in-service monitoring is possible. This capability can lead to significant decrease in operation and maintenance costs because the structure will only be removed and patched when the in-service health data indicate it is necessary.

\section{Transient Events Lead to Damage and Failure}

In addition to the natural slow fatigue of the blade structure, there is also significant concern about transient impacts and loads due to environmental factors. Oceans and rivers are actually heterogeneous bodies of water that contain aquatic and marine organisms, vegetation due to runoff, and pollution that pose a significant hazard to hydrokinetic energy systems. Multiple reports have been published evaluating the effect of hydrokinetic energy systems on marine life (e.g., fish and other aquatic organisms, diving birds, and mammals). ${ }^{11-14}$ Coutant and Cada have 
estimated the impact zone for fish in a free-flow turbine ${ }^{14}$ and a schematic of this zone is shown in Figure 4. When the turbine blade delivers a strike to the organism, the organism also delivers a strike to the blade! While a single impact may not be immediately catastrophic, it can create a crack at the point of impact that eventually propagates, compromising the structural integrity of the blade and leading to failure. In addition, other transient environmental effects may cause increased loads on the blade, degrading structural integrity. For example, earthquakes, tsunamis, and flooding are all natural phenomena that will occur and may cause damage.

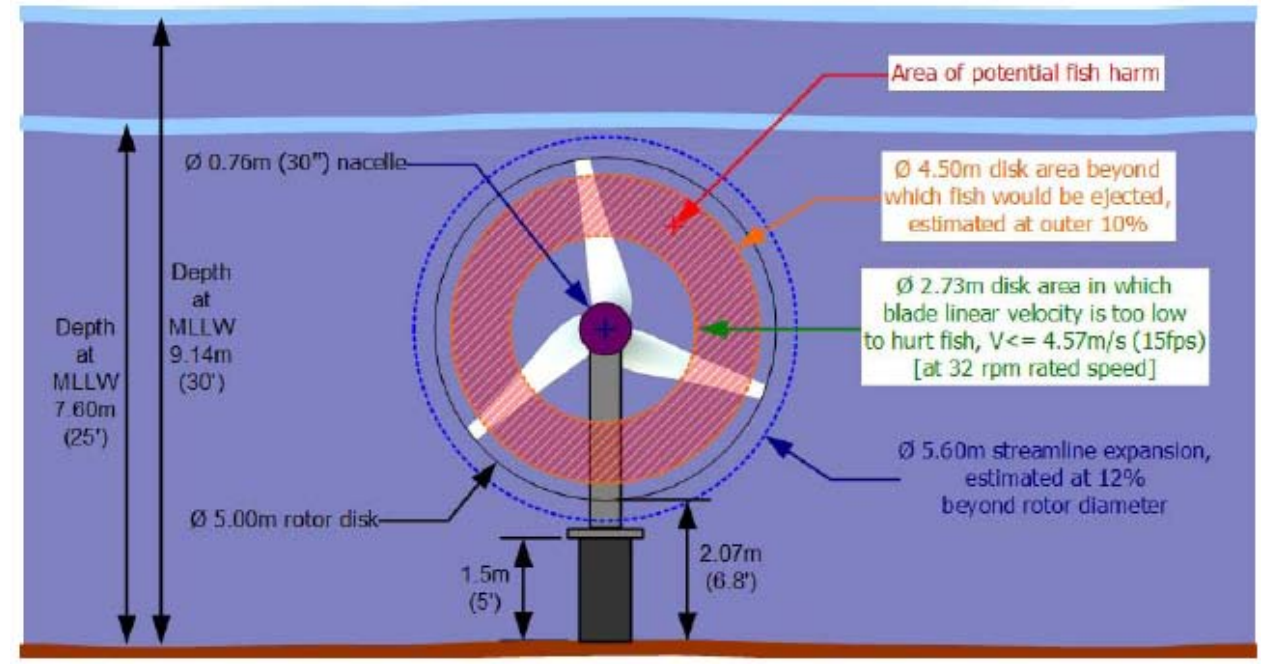

Figure 4: Hypothetical zone of potential damaging strike associated with a submerged free-flow turbine. ${ }^{14}$

\section{Remote Monitoring is Crucial}

Blade structural health needs to be monitored remotely. By their very nature the blades of a hydrokinetic energy system must be remotely located in areas that are generally difficult to view, inspect, and analyze. The turbine blades are placed underwater either in a river or ocean. What's more, many hydrokinetic energy systems plan to be located off-shore or in remote areas far from dense population. For example, a study of potential Alaska river in-stream power plants selected three river locations where the nearest villages have populations of 50-100 people and the nearest cities are 100's of miles away. ${ }^{15}$ Simply getting to these sites represents a significant challenge. Accessing the components to perform any kind of analysis would be a difficult, expensive, and nearly impossible task.

\section{Lower Operation \& Maintenance Costs Enhance Investment Returns}

There are multiple scenarios where remote monitoring of turbine blade structural health is beneficial. For example:

1) It can lead to timely replacement of parts by notifying service personnel when the blade structural integrity is likely to soon fail.

2) In the event of damage due to transient environmental effects, the remote monitor would immediately notify service personnel so the system could be repaired quickly to minimize down-time. 
3) Knowledge of the turbine blade structural health could lead to enhanced operational lifetime. For example, as the blades age, the system may be operated at reduced capacity to reduce structural load, thereby maintaining power generation (albeit at a reduced level) for a longer period of time.

All of these scenarios lead to the main benefits, which are lower operation and maintenance (O\&M) costs and a higher return on investment. The Pew Center on Global Climate Change recently found that one of the major challenges associated with hydrokinetic energy systems is O\&M costs. Specifically, the report states that "O\&M costs could remain high due to difficult access and working conditions unless machines are developed that can be unattended for long periods of time." ${ }^{\prime 6}$ In other words, leaving hydrokinetic systems unattended and remotely monitoring them is imperative for reducing O\&M costs and making it a viable and promising technology.

It is difficult to estimate the future O\&M costs of hydrokinetic systems because the technology is still being developed. However, wind energy systems are plagued by similar issues and, over the lifetime of the machine, have typical O\&M costs of 70-95\% of the total investment cost. ${ }^{17}$ A substantial fraction! These estimates were for a project that considered 600, $750 \mathrm{~kW}$ wind turbines. O\&M costs are typically higher for smaller power machines and near-term hydrokinetic systems are likely to be a few $100 \mathrm{~kW}$, in which case O\&M costs may be higher. In other words, reducing O\&M costs with remote monitoring may be the only salvation for making these systems viable on a large scale with widespread use.

\section{State of the Art of Remote Structural Health Monitoring}

Application of remote monitoring technology to hydrokinetic energy systems is still in its infancy. Technologies exist to remotely monitor some of the hydrokinetic system operational parameters, such as voltage, frequency, and power output. However, the ability to monitor the health of the structure, specifically, the most important structural component, the turbine blade, has yet to be developed.

Remote monitoring of systems is not a new idea. The medical community has been remotely monitoring the status of hospital in-patients for the past decade via network connections. Further, pacemakers and implantable cardioverter defibrillators (ICDs) are implanted inside the human body and then monitored remotely by the physician after the patient returns home. ${ }^{18}$ Remote monitoring of traditional energy systems has also been developed. Specifically, the oil and gas companies remotely monitor the pressure and flow in pipelines. ${ }^{19}$ These are generally referred to as SCADA (supervisory control and data acquisition) systems and are commonly used for manufacturing, production, and other industrial processes. These systems are not uncommon and have also been proposed for use with hydrokinetic systems. Specifically, the Alaska report for river in-stream systems suggests that the hydrokinetic system will require "real time satellite-based SCADA monitoring that includes voltage/frequency/power output, fault alarms, and webcams." ${ }^{\prime 15}$

\section{Energy System Monitoring}

The state-of-the-art in renewable energy system monitoring is wind turbine energy systems. Monitoring of the system when it is operational is generally referred to as on-line monitoring. 
This type of monitoring can be incorporated into SCADA systems to automatically trigger appropriate alarms and alert staff when a problem occurs. This feature is essential for unattended turbine operation, especially in remote or inaccessible locations. ${ }^{17}$ All commercial turbines incorporate basic on-line monitoring. Generally the control system includes sensors to monitor machine parameters such as temperatures, speeds, fluid levels, line phase imbalance, voltage levels, and tower vibration. This level of monitoring is used to confirm that the turbine is operating correctly, that the lubrication and cooling systems are functional, and that an unsafe condition has not occurred. This basic level of monitoring is usually the only means for observing the turbine during operation. Structural health monitoring technology is being developed, has been demonstrated, but is not yet common for wind turbine systems.

\section{Structural Health Monitoring}

As important as the wind turbine blades are to the system, an on-line method for monitoring the structural health of these components is still being developed. Structural health monitoring of hydrokinetic turbine blades has not yet been pursued. The purpose of the proposed project is to demonstrate monitoring of the structural health of a hydrokinetic turbine blade and show how this can be incorporated into the overall SCADA system monitoring component.

There are many techniques for monitoring the health of any structural component, including wind and hydrokinetic turbine blades. However, most of these techniques are off-line monitoring technologies, which mean they cannot be used on a system while it is operating. For example, acoustic emissions, thermal imaging, ultrasonic detection, fiber optics, laser Doppler vibrometry, electrical resistance-based damage detection, strain memory allow methods, $\mathrm{x}$ radioscopy methods, and eddy current methods have all been used to assess the structural integrity of a wind turbine. ${ }^{20}$ However, of these methods, only acoustic monitoring has been used in the field to transmit data from the blade to a ground station. ${ }^{20-22}$

The state-of-the-art in structural health monitoring is wind turbine blade monitoring using acoustic emission data radio-transmitted from the blade. The challenge with on-line monitoring the structural health of the turbine blade is that it is a rotating component that is always moving when the system is operating. So connecting a wire to a fiber optic, acoustic sensor, electrical strain gage, etc. is not practical. In other words, structural health data need to be acquired and then wirelessly transmitted from the rotating frame of the blade. This was the approach that successfully showed radio transmission acoustic monitoring of a wind turbine blade. ${ }^{20-22}$ Simply adapting this system to a hydrokinetic turbine blade is not possible because in an aquatic environment radio waves do not travel very far and require high power.

The proposed project plans to demonstrate wireless transmission of structural health information from a turbine blade within an aquatic environment. Specifically, structure strain data will be transmitted acoustically since radio waves do not travel far in an aquatic environment. Because data are transmitted acoustically, acoustic monitoring of the blade is not possible and a fiber optic strain measurement technique will be employed.

\section{Original Component TRL Self-categorization - Was at TRL 1}

This section describes work and tasks that have already been completed for the proposed component concept. Because of this previous work, the component is at TRL 1. This means that 
the basic principles for the component have been observed and the essential characteristics and behaviors have been verified. In other words, we know that composite materials with embedded sensors can be fabricated and we know that underwater acoustic signals can be transmitted and received. We do not know if these two technologies can be linked to provide real-time communication of the material structural health. Specific tasks that have been completed to justify TRL 1 are:

1) Feasibility study of the basic and operational characteristics of the technology. The three important questions to answer to determine the feasibility of the technology are: "Can a hydrokinetic composite turbine blade with embedded fiber optic strain gage be fabricated?", "Can data be transmitted underwater acoustically?”, and, if so, "Can the fiber optic strain gage data be transmitted acoustically?" Based on the feasibility study, the answer to these three questions is "yes". Fiber optic strain gages are commonly used to measure the strain within a structure and have been embedded in composite laminate structures. $^{20,23-25}$ Underwater acoustic transmission of data is currently an active area of research focusing on higher data rates and networking. ${ }^{1,26}$ However, the most basic form of underwater data transmission is frequency-modulated communication where the acoustic signal frequency is adjusted based on the input data. ${ }^{27}$ Fiber optic strain gage data can be transmitted acoustically if the strain data ( DC, slowly varying) can be converted into an acoustic (oscillating, AC, 20-60 kHz) signal. Fortunately this type of signal conditioning is commonly done with integrated circuits called voltage-controlled oscillators, which convert a DC input voltage into an oscillating output with frequency proportional to the input magnitude. ${ }^{28}$

2) Identification of the technical and economic merits. Turbine blades are the most important structural component of the energy production system, so there is economic incentive to monitor their health so that timely maintenance, longer life, and damage notification are possible. This technology has the potential to reduce operation \& maintenance (O\&M) costs for hydrokinetic systems, costs which will likely make-up 70$95 \%$ of the total system investment cost. ${ }^{17}$ O\&M costs will likely remain high due to difficult access and working conditions unless machines are developed that can be remotely monitoring and unattended for long periods of time. ${ }^{16}$ Further, composite materials are more durable, lighter weight, and less corrosive than metals commonly used for hydrokinetic turbine blades.

3) Preliminary design and engineering has been completed for a proof-of-concept component test that demonstrates acoustic transmission of structural health data from a composite turbine blade with embedded fiber optic strain gage. Based on this design, the devices to be used for testing have been determined and are described in subsequent sections.

\section{E. Plan to Advance Component to TRL 3}

Tasks required to advance to TRL 3 that have not yet been completed and are part of the proposed project are:

1) Small scale prototyping and testing of the component to reduce uncertainty and validate high-level assumptions 
2) Developing higher fidelity estimates of values such as component size, weight, layout, power, and performance.

3) Assessing commercial off the shelf equipment that can be employed within the component.

4) Assessment of risks and barriers, and development of a follow-on plan that seeks to further prove the component concept and advance the TRL from 3 through 7.

Based on the tasks required for TRL 3, the proposed project objective is proof-of-concept validation of the component concept by remotely monitoring the strain within a hydrokinetic turbine blade as it is subjected to known loads. Specific objectives include fabricating a turbine blade with embedded fiber optic strain gage, demonstrating underwater acoustic transmission of strain data, verifying wireless broadcast of data to a receiver station, analysis of sensor and acoustic transmitter power requirements, and determination of optimum component installation in hydrokinetic energy systems. The proposed research plan of work seeks to experimentally demonstrate the critical function of the structural health monitoring component, thereby proving the concept and raising the TRL to 3.

The critical function of the structural health monitoring component is to sense the strain on the blade and transmit this information to the control center. This main function must be completed in multiple steps as shown in Figure 1. First, the strain in the blade must be measured by a suitable sensor. Then the data must be transmitted from the rotating reference frame of the blade to a stationary receiver. In the aquatic environment of hydrokinetic systems, the data transfer must occur underwater via acoustic communication. Finally, the relay center broadcasts the structure strain information via radio waves to the monitoring center.

The work plan to accomplish the objectives is divided into three main groups of tasks: structure \& monitoring sensor development, acoustic communication \& broadcasting development, and assembled component testing. These three groups are described in detail in the following sections and are summarized in the timeline in Table 1 below. The work plan is designed to first independently test and verify each of the steps required for the structural health monitoring component to function correctly. Specifically, we will design and fabricate the turbine blade with an embedded fiber optic sensor and verify accurate strain results. At the same time, we will develop the acoustic and wireless broadcasting capability to transmit data. Then these technologies will be integrated and the assembled structural health monitoring component evaluated. 
Table 1: Timeline for the tasks of the project.

\begin{tabular}{|l|l|l|l|l|l|l|l|l|l|l|l|l|l|}
\hline \multicolumn{1}{|c|}{ Task } & Oct. & Nov. & Dec. & Jan. & Feb. & Mar. & Apr. & May & June & July & Aug. & Sept. \\
\hline Structure \& Monitoring Sensor Development & & & & & & & & & & & & \\
\hline 1 - Blade Finite Element, Vacuum Infusion Modeling & & & & & & & & & & & & \\
\hline 2 - Blade Fabrication with Embedded Sensor & & & & & & & & & & & & \\
\hline 3 - Testing Comparison with Electrical Strain Gage & & & & & & & & & & & & \\
\hline Acoustic Comm. \& Broadcasting Development & & & & & & & & & & & & \\
\hline 4 - DC - AC Signal Converter Fabrication & & & & & & & & & & & & \\
\hline 5 - Acoustic Transducer - Hydrophone Testing & & & & & & & & & & & & \\
\hline 6 - Bluetooth Integration & & & & & & & & & & & & \\
\hline Assembled Component Testing & & & & & & & & & & & & \\
\hline 7 - Continuous Strain Monitoring & & & & & & & & & & & & \\
\hline 8 - Component Proof-of-Concept Assessment & & & & & & & & & & & & \\
\hline
\end{tabular}

\section{Results and Discussion}

\section{A. Structure \& Monitoring Sensor Development}

Smart structures approaches use in-situ sensors and related instrumentation to provide in-service structural monitoring. The performance of composite structures has been frequently studied through parallel theoretical modeling and experimental testing. Load-induced strain is an important parameter that can be readily measured. Damage or degradation to a composite structure, e.g. delamination and fiber breakage, will change the static and dynamic strain behavior. A strain signature due to a well-defined load case, such as cyclic operation, is a means of damage assessment. Consequently, a health monitoring system can be based on strain measurement.

For long-term monitoring of a structure, the choice of sensor becomes important. The sensor must be rugged for field use, must have a long operating life, and must be compatible with the host structure. Smart sensor instrumentation of composite structures has been implemented with piezoelectric and fiber optic approaches. Notably, fiber optic sensors have the capability of being embedded in a composite structure without degrading the host structure. These sensors have advantages of small size, temperature tolerance, high sensitivity, environmental adaptability, etc.

In this work, composite blade performance and instrumentation are investigated. Simple fourlayer and eight-layer composite beams and three-dimensional, eight-layer blades are considered for free-vibration and static loading. These structures are carbon/epoxy, symmetric composite laminates that were manufactured using an autoclave process. Experimental results for strain measurements from electrical resistance gages are presented in preparation for later embedded sensors. Also, theoretical strain characteristics are presented from in-house, finite-element analysis for all sample cases. Finally, a health monitoring system is proposed that is based on embedded strain sensors and embedded motes in which strain information is demodulated for wireless transmission. 


\section{Structures}

\section{a. Hydrokinetic Turbine Operation}

Rotating blade and turbine arrangements are an important form of hydrokinetic technology [1]. System components are the turbine blades, the turbine generator, and power converter. The blades are submerged to capture the kinetic energy of the flowing water current. Blades may be incorporated into horizontal-axis designs or vertical-axis designs. For efficient energy generation, the location must be chosen with regard to strong tides or current flow. For instance, good locations for river applications have natural or argumentation channels to enhance fluid flow. Locations are further constrained by other river uses (e.g. shipping and fishing), seasonal current variations, and environmental impact. For economical operation, key considerations include service life, maintenance needs, and operating costs. The system, and the blades in particular, must operate in possible remote locations and under extreme conditions. The blades are exposed to potentially damaging impacts from debris, ice, etc. Without timely intervention, minor damage may progress to catastrophic failure.

Composite blade structures are well suited for these hydrokinetic applications. With the appropriate constituent materials, composite blades have a long life in marine environments. The structural performance of such blades can be tailored to meet the requirements of hydrokinetic turbines similar to related composite blade designs for wind turbines and aircraft propellers. The compatibility of composite structures with in-situ instrumentation is explored in this work.

\section{b. Sample Composite Beams and Blades}

The composite samples used for the experiments were fabricated using an autoclave process in the Composite Fabrication Laboratory at Missouri University of Science and Technology. The samples were multilayer carbon/epoxy laminates. Both beam and blade designs were studied. The initial tests were performed on four-layer beams of dimensions $20.32 \mathrm{~cm}$ x $2.54 \mathrm{~cm}$ x 0.0508 $\mathrm{cm}$ (not including the cantilever clamping area). Each laminate of this beam is $0.127 \mathrm{~mm}$ thick. A symmetric lay-up sequence of [0/90/90/0] was used with the material ACG(MTM 451/HTS563112k).

The next tests were done with eight-layer beams and an eight-layer blade fabricated from identical $0.127-\mathrm{mm}$ laminates. The beam dimensions were $20.32 \mathrm{~cm}$ x $2.54 \mathrm{~cm} \times 0.101 \mathrm{~cm}$ (not including the clamping area). The blade length was $27.94 \mathrm{~cm}$ (not including the clamping area). For both, a symmetric lay-up sequence of [90/90/0/0/0/0/90/90] was used with the material Cytec Cycom 5250/AS4. Figure 5 shows the blade design and Table 2 gives the position, chord length, and thickness of cross-sectional stations measured from the blade root. The material properties are shown in Table 3. 


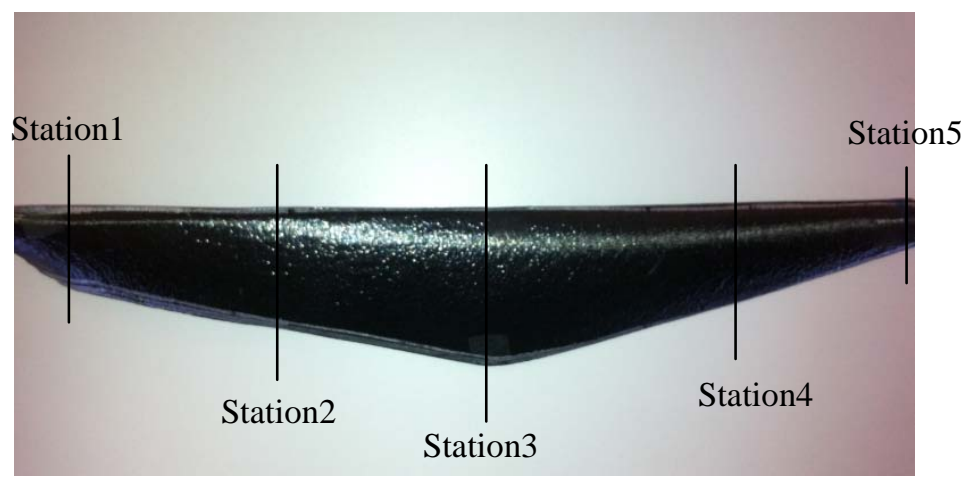

\section{Figure 5 Composite Blade.}

Table 2: Design of the Composite Blade.

\begin{tabular}{|c|c|c|c|}
\hline Blade Station & Position from Root $(\mathrm{cm})$ & Chord Length $(\mathrm{cm})$ & Thickness $(\mathrm{cm})$ \\
\hline \hline 1 & 2.54 & 3.05 & 0.101 \\
\hline 2 & 8.89 & 4.06 & 0.101 \\
\hline 3 & 15.24 & 5.46 & 0.101 \\
\hline 4 & 22.86 & 3.56 & 0.101 \\
\hline 5 & 30.48 & 1.52 & 0.101 \\
\hline
\end{tabular}

Table 3: Material Properties of the Composite Beams and Blade.

\begin{tabular}{|c|c|c|}
\hline Properties & Four-Layer Beam & $\begin{array}{c}\text { Eight-Layer Beam and } \\
\text { Blade }\end{array}$ \\
\hline \hline Young's Modulus & $\mathrm{E}_{11}=138 \mathrm{GPa}$ & $\mathrm{E}_{11}=143 \mathrm{GPa}$ \\
$\mathrm{E}_{22}=\mathrm{E}_{33}=8.96 \mathrm{GPa}$ & $\mathrm{E}_{22}=\mathrm{E}_{33}=10.19 \mathrm{GPa}$ \\
\hline Poisson's Ratio & $v_{12}=v_{13}=\mathrm{v}_{23}=0.3$ & $v_{12}=v_{13}=\mathrm{v}_{23}=0.3$ \\
\hline \multirow{2}{*}{ Shear Modulus } & $\mathrm{G}_{12}=\mathrm{G}_{13}=7.10 \mathrm{GPa}$ & $\mathrm{G}_{12}=\mathrm{G}_{13}=4.01 \mathrm{GPa}$ \\
$\mathrm{G}_{23}=6.8 \mathrm{GPa}$ & $\mathrm{G}_{23}=3.7 \mathrm{GPa}$ \\
\hline Density & $\rho=1600 \mathrm{~kg} / \mathrm{m}^{3}$ & $\rho=1580 \mathrm{~kg} / \mathrm{m}^{3}$ \\
\hline
\end{tabular}

c. Finite Element Analysis of Composite Structures

A finite-element analysis (FEA) was done using in-house code to predict beam and blade behavior. Cantilever boundary conditions were assumed. The static strain was calculated for a given tip deflection. A free-vibration (dynamic) case was calculated in which the first and second natural frequencies (bending mode) were determined. Figure 6 illustrates the strain distribution from the FE model for top surface of beam under deflection. The beam is supported on the left end. Figure 7 illustrates the strain distribution from the FE model for top surface of blade under deflection. The beam is supported on the left end.

Figure 8 shows the active area of a strain gage on a beam. The FE model calculated the strain at points A, B, and C. Location B is the center of the gage and locations $\mathrm{A}$ and $\mathrm{C}$ are at the extremes of the gage. An average strain from these three locations was used for comparison to the distributed strain measured by the experimental sensor. The same procedure was used for the blade FE model. 

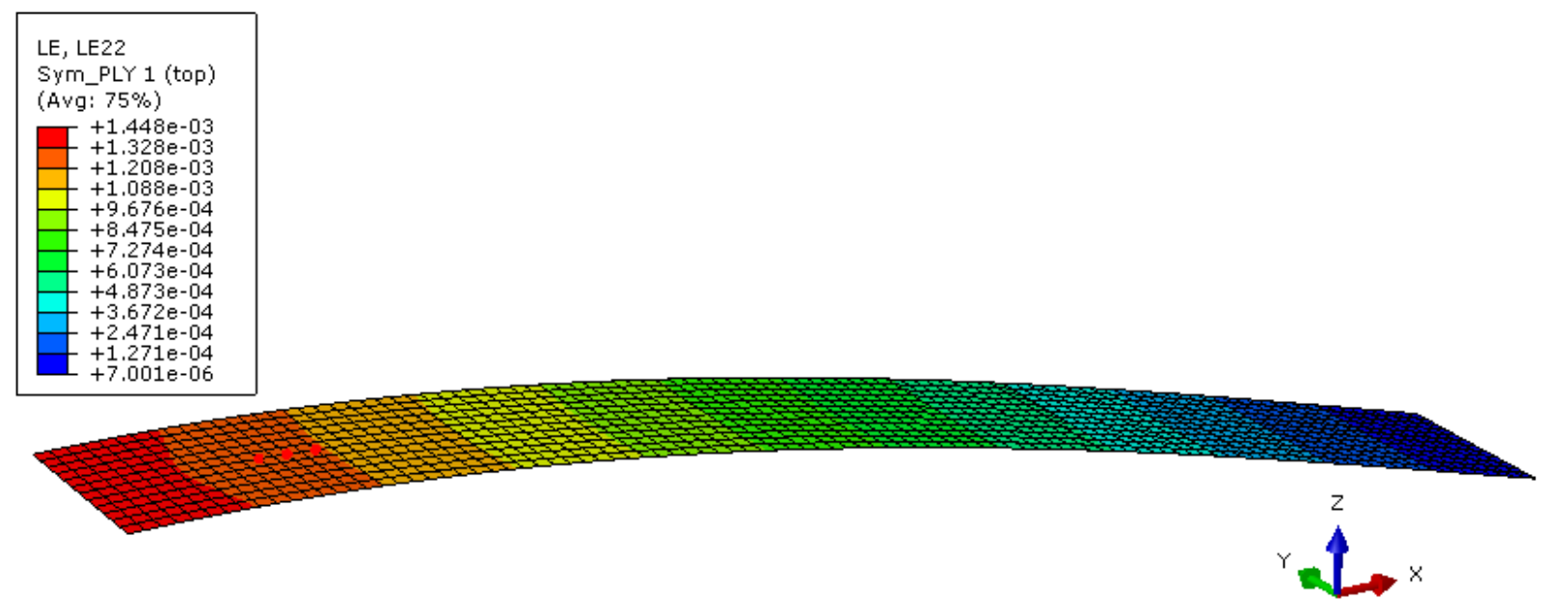

Figure 6: Strain Distribution of the Composite Beam along the Beam Length (x Direction) for Support on the Left End.

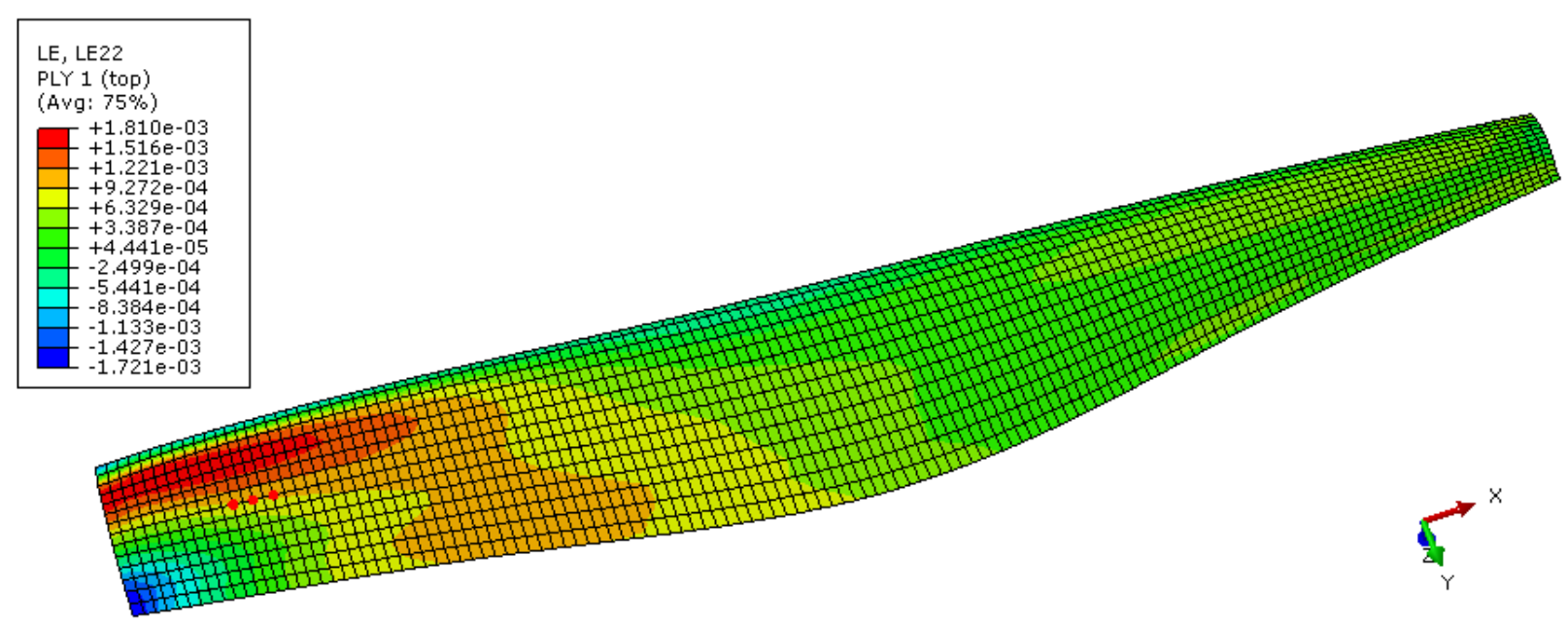

Figure 7: Strain Distribution of the Composite Blade along the Blade Length (x Direction) for Support on the Left End 


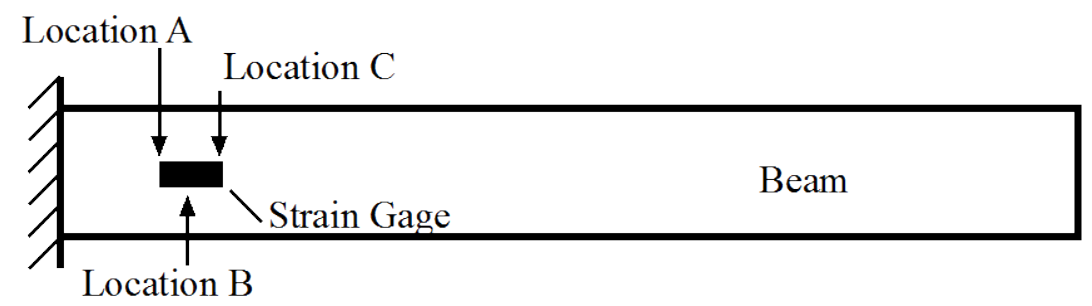

Figure 8: Strain Gage Active Area. The FE Model Calculates Strain at Locations A, B, and $C$.

\section{Experimental Procedures}

a. Static Strain and Free-Vibration Strain Measurements

The initial test case was for static flexural strain. The procedure was to clamp the beam or blade as a cantilever as shown in Figure 9. In the beam test, the tip was deflected $3.81 \mathrm{~cm}$ and the strain measured. In the blade test, the tip was deflected $2.54 \mathrm{~cm}$ and the strain measured near the clamped end.

The dynamic test case measured free vibration. Again, the beam or blade was clamped as a cantilever. The tip was deflected $3.81 \mathrm{~cm}$ and $2.54 \mathrm{~cm}$ for the beam and blade, respectively. After release, the instrumentation captured the strain transient signal. The content of the strain transient was analyzed and the first natural frequency was recorded.
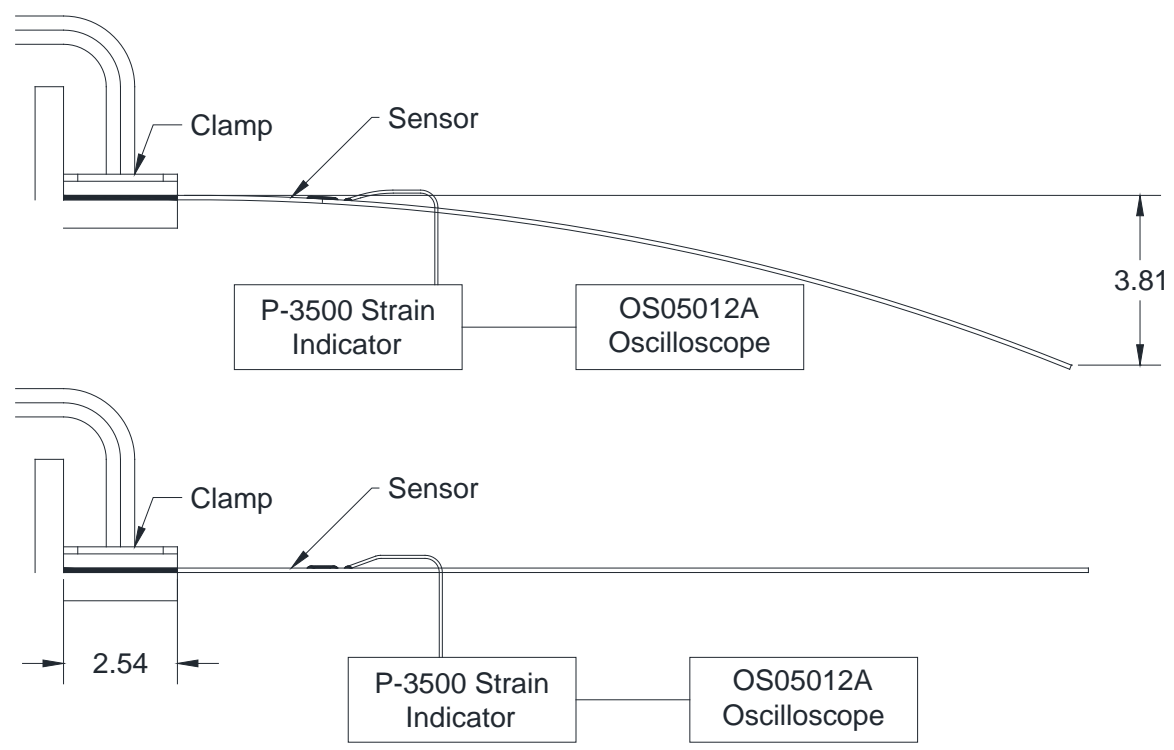

Figure 9: Experimental Setup for Static Strain Test (dimensions in cm) 


\section{b. Strain Instrumentation}

Strain gage sensors were mounted for flexure strain with the gage mid-points located $2.54 \mathrm{~cm}$ from the support. Figure 10 and Figure 11 show the sensor layout for the beam and blade, respectively. The shaded regions are for the clamp support. The overall cantilever lengths were $20.32 \mathrm{~cm}$ and $27.94 \mathrm{~cm}$, respectively. The gages are centered along the midline of the beams and located $0.64 \mathrm{~cm}$ from the leading edge of the blade.

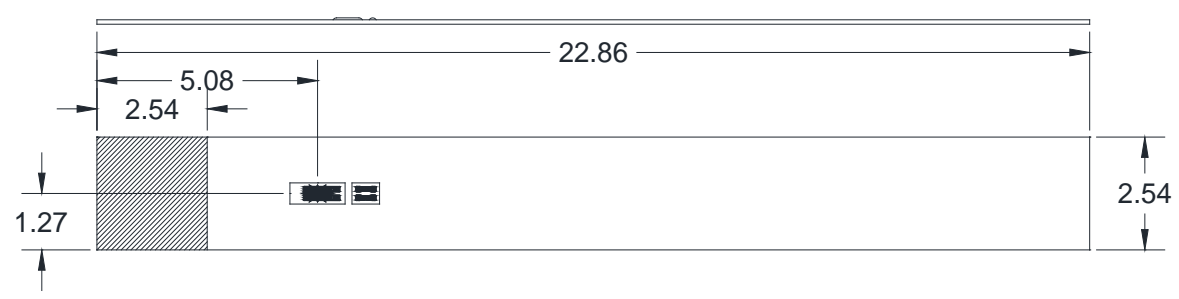

Figure 10: Carbon/Epoxy Composite Beam with Sensor Layout (dimensions in cm)

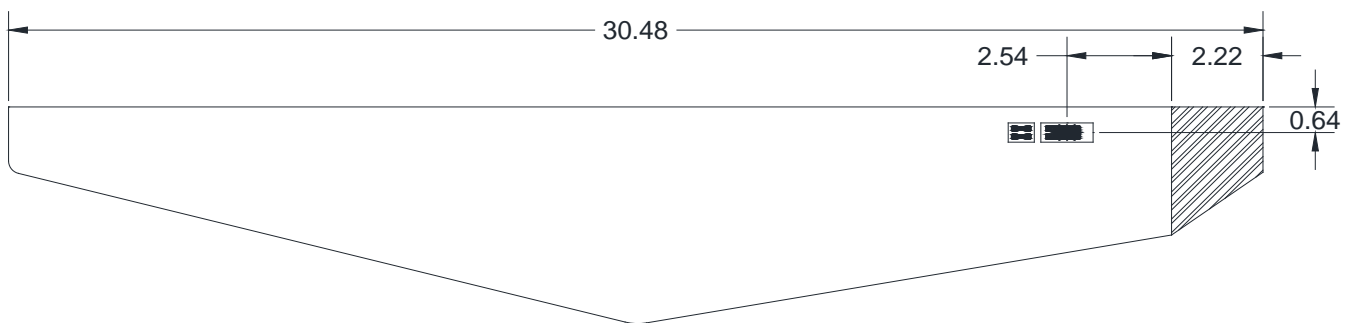

Figure 11: Carbon/Epoxy Composite Blade with Sensor Layout (dimensions in cm)

The strain sensors for the experimental beam and blade tests were $120-\Omega$ electrical resistance gages (Micro-Measurements EA series with 6.35-mm active length). The gages were surface mounted with M-Bond 200 adhesive. The support instrumentation was a Wheatstone bridge strain indicator (Micro-Measurements P-3500) and an oscilloscope.

3. Results and Analysis

a. Beam Tests

The static strain test results for the four-layer and eight layer beams are shown in Table 3. The tip deflection was $3.81 \mathrm{~cm}$. The experimental strain value is compared to the average theoretical strain from the FE model. The average theoretical strain was calculated from the strain at the center of the gage (location B) and the extremes of the gage (location A and C) as shown in Figure 8. The average experimental strain was calculated from multiple measurements on the same beam. The static strains matched within $5.9 \%$ and $6.9 \%$ for the four-layer and eight-layer beams, respectively. The percent difference was calculated as

| (Theoretical Average - Experimental Average)/ (Theoretical Average) |x 100. 
Table 4: Static Strain Results for the Composite Beams.

\begin{tabular}{|l|l|l|l|l|l|l|}
\hline Beam Type & $\begin{array}{l}\text { Theoretical } \\
\text { Strain at A } \\
\text { (microstrain) }\end{array}$ & $\begin{array}{l}\text { Theoretical } \\
\text { Strain at B } \\
\text { (microstrain) }\end{array}$ & $\begin{array}{l}\text { Theoretical } \\
\text { Strain at C } \\
\text { (microstrain) }\end{array}$ & $\begin{array}{l}\text { Theoretical } \\
\text { Average } \\
\text { (microstrain) }\end{array}$ & $\begin{array}{l}\text { Experimental } \\
\text { Average } \\
\text { (microstrain) }\end{array}$ & $\begin{array}{l}\text { Percent } \\
\text { Difference }\end{array}$ \\
\hline $\begin{array}{l}\text { Four-Layer } \\
\text { Beam }\end{array}$ & 628.49 & 615.74 & 596.91 & 613.71 & $650 \pm 5$ & $5.9 \%$ \\
\hline $\begin{array}{l}\text { Eight- } \\
\text { Layer } \\
\text { Beam }\end{array}$ & 1274.39 & 1248.60 & 1209.55 & 1244.18 & $1230 \pm 5$ & $6.9 \%$ \\
\hline
\end{tabular}

The free-vibration test results for the eight-layer beam are shown in Table 5 and Figure 12. The tip deflection was $3.81 \mathrm{~cm}$. The first and second natural frequencies from the FEA model are shown. Both frequencies refer to bending modes. The experimental result for the first natural frequency is shown; the second natural frequency was not recorded due to instrument limitations. The experimental frequency closely matched the theoretical prediction.

Table 5: Free-Vibration Results for the Eight-Layer Composite Beam.

\begin{tabular}{|l|l|l|l|}
\hline & \multicolumn{2}{|l|}{ Theoretical Natural Frequencies $(\mathrm{Hz})$} & Experimental Natural Frequency (Hz) \\
\hline \hline Eight-Layer Beam & $1^{\text {st }} 16.40 \mathrm{~Hz} \quad 2^{\text {nd }} 102.7 \mathrm{~Hz}$ & $1^{\text {st }} 16.1 \mathrm{~Hz}$ \\
\hline
\end{tabular}

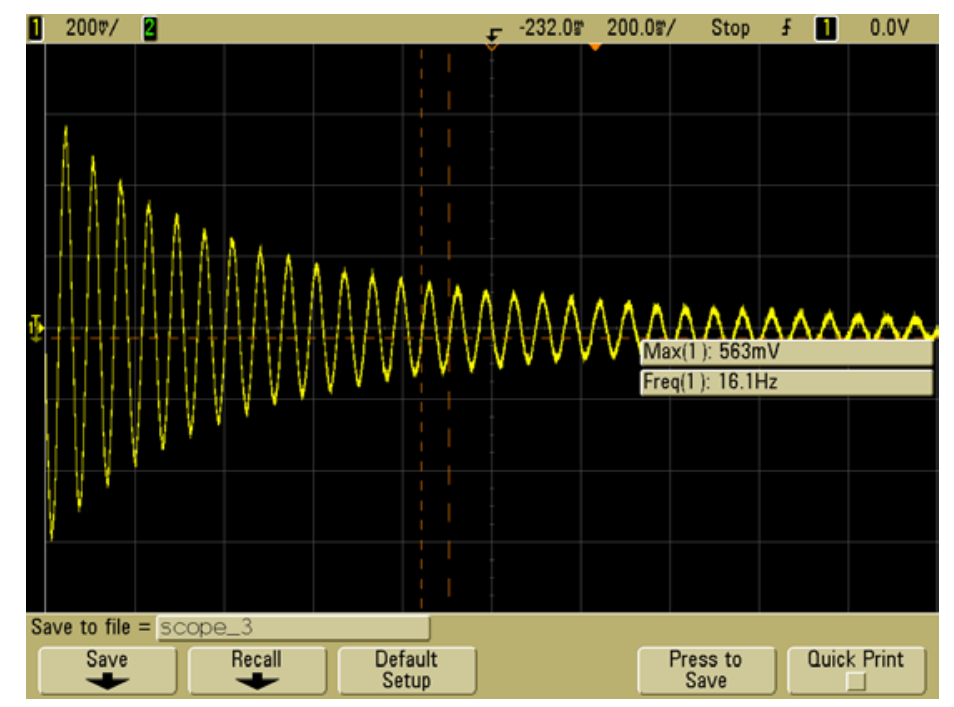

\section{Figure 12: Free-Vibration Strain Transient for the Eight-Layer Composite Beam}

b. Blade Tests

The static strain test results for the blade are shown in Table 6. The tip deflection was $2.54 \mathrm{~cm}$. The experimental strain value is compared to the theoretical strain, i.e. the average strain of the ABC locations, from the FE model. The percent difference is calculated as for the beam tests. The static strains differ by $16.4 \%$. Note that the theoretical strain varies significantly over the gage active area. 
The free-vibration test results for the blade are shown in Table 7. The strain transient is similar to that in Figure 12. The first and second natural frequencies from the FEA model are shown. Both frequencies refer to bending modes. Here the first natural frequency differs by more than a factor of two. The cause of this difference is not clear and will be explored in future tests.

Table 6: Static Strain Results for the Composite Blade.

\begin{tabular}{|l|l|l|l|l|l|l|}
\hline Type & $\begin{array}{l}\text { Theoretical } \\
\text { Strain at A } \\
\text { (microstrain) }\end{array}$ & $\begin{array}{l}\text { Theoretical } \\
\text { Strain at B } \\
\text { (microstrain) }\end{array}$ & $\begin{array}{l}\text { Theoretical } \\
\text { Strain at C } \\
\text { (microstrain) }\end{array}$ & $\begin{array}{l}\text { Theoretical } \\
\text { Average } \\
\text { (microstrain) }\end{array}$ & $\begin{array}{l}\text { Experimental } \\
\text { Average } \\
\text { (microstrain) }\end{array}$ & $\begin{array}{l}\text { Percent } \\
\text { Difference }\end{array}$ \\
\hline \hline Blade & 704.51 & 813.17 & 1111.04 & 876.24 & $1020 \pm 5$ & $16.4 \%$ \\
\hline
\end{tabular}

Table 7: Free-Vibration Results for the Composite Blade.

\begin{tabular}{|l|l|l|l|}
\hline & \multicolumn{2}{|l|}{ Theoretical Natural Frequencies (Hz) } & Experimental Natural Frequency (Hz) \\
\hline \hline Blade & $1^{\text {st }} 38.63 \mathrm{~Hz} \quad 2^{\text {nd }} 76.04 \mathrm{~Hz}$ & $1^{\text {st }} 15.6 \mathrm{~Hz}$ \\
\hline
\end{tabular}

\section{B. Acoustic Communication and Broadcasting Development}

In the following sections we describe our proof-of-concept demonstration of the data transmission part of the blade structural health monitoring concept. In the following study, a simulated strain gage output was used as the input to the data transmission system. The system was demonstrated in both a bench top environment and on a prototype hydrokinetic turbine in a laboratory environment (water tunnel). In addition to demonstrating the feasibility of the technique, we also present results from a power analysis that is used to assess the viability of the approach and its suitability for both commercial and prototype hydrokinetic energy systems. We envision this novel concept and the resulting capability to enable blade structural health monitoring in both long-term commercial hydrokinetic system deployment, as well as in prototype environmental impact studies.

1. Data Transmission Process and System

Remote monitoring of the structural health of a hydrokinetic turbine blade requires transfer of data from the measurement location to the monitoring station. For the concept investigated here, structural health data are acquired using internal turbine blade diagnostics (fiber optic strain gages) and this information is acquired within the rotating reference frame of the blade. Data must be transferred from the blade to the remote monitoring station. A schematic of the data transfer process is shown in Figure 13. The structural health data (strain gage output) are transmitted underwater from the rotating frame of the turbine blade to a nearby stationary underwater receiver. The data can then be broadcast wirelessly using one of many conventional techniques (RF, Bluetooth, microwaves, etc.) to notify the remote monitoring station. 


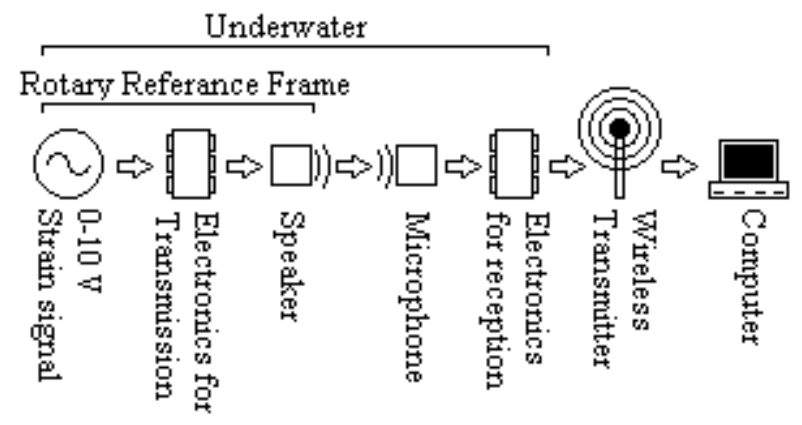

\section{Figure 13: Schematic of main components of the underwater acoustic communication system.}

The system described here uses an acoustic communication system for underwater data transmission, while the above water (air) data transmission uses a wireless Bluetooth transmitter. As shown in Figure 13, a 0-10 V source simulates the data output from a strain gage embedded in the turbine blade ${ }^{18}$. This data signal is encoded by the transmitter electronics and acoustically transmitted through the water. The encoded data signal is received by an underwater microphone connected to the receiver electronics, which then decode the signal and broadcast it wirelessly through air via Bluetooth. A remote computer with a Bluetooth receiver serves as the remote monitoring station.

The following sections describe the details of the data transmission system. First the transmitter and receiver circuitry are described. Then the rationale for selecting $40 \mathrm{kHz}$ as the underwater acoustic transmission frequency is explained. Next the prototype software used to operate both the transmitter and receiver electronics, and encode and decode the data, is described. Finally, the bench top setup, hydrokinetic energy system, and water tunnel used for testing are described.

\section{a. Acoustic Transmitter and Receiver Circuitry}

The acoustic transmitter and receiver circuits consist of two main components: a microcontroller and an ultrasonic transducer. The foundation of the transmission and reception circuitry are two PIC18F46K20 Microchip microcontrollers (MCUs), one for each circuit. These MCUs provide the necessary processing to encode and decode the data. They were selected because they have a variety of useful built-in features, such as several analog to digital conversion (ADC) ports, the capability of implementing EUSART serial communication, and an extremely low power consumption when 'sleeping.' A pair of MA40MF14-5B Murata ultrasonic transducers serve as the acoustic transmitter and receiver. These transducers are optimized for $40 \mathrm{kHz}$ frequency, and were selected based on the rationale described below. 


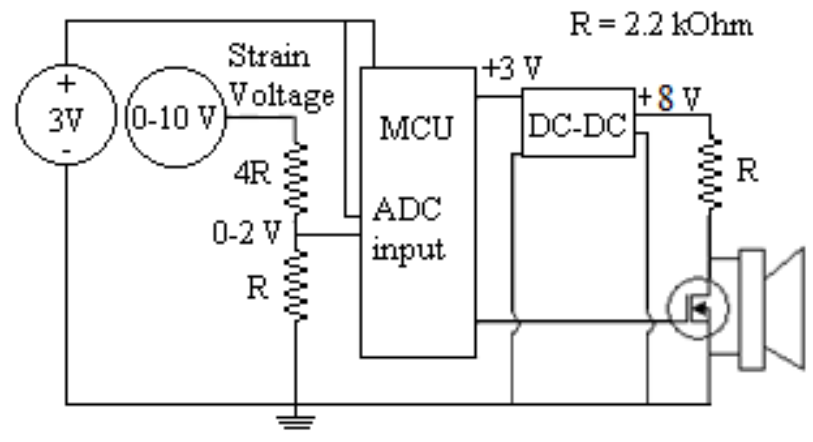

\section{Figure 14. Transmitter Circuit}

The main tasks of the transmitter circuit are to measure the strain sensor voltage, measure the battery voltage, enter and awake from "sleep" mode, encode the strain data into an acoustic signal, and transmit the data with the ultrasonic transducer. A schematic of the transmitter circuit is shown in Figure 14. Measuring the sensor voltage and battery voltage is done using the MCUs built-in ADC feature. Measuring the battery voltage allows us to also track the life of the power supply. The voltage divider at the strain sensor is used to lower the 0 to $10 \mathrm{~V}$ simulated strain gage signal to 0 to $2 \mathrm{~V}$, since the MCU input pins can only take 0 to $5 \mathrm{~V}$. The effect of duty cycle on the potential lifetime of the monitoring system is studied in subsequent sections by using the "sleep" feature of the MCU, which is controlled using the MCU software. MCU software is also used to encode the measured strain gage voltage into the acoustic transmission signal. Transmission of the acoustic signal uses the $40 \mathrm{kHz}$ ultrasonic transducer, a DC to DC converter, and a logic level mosfet. While initial tests showed that the MCU alone can drive the transducer, the resulting ultrasonic signal was too weak to ensure accurate reception. Instead a simple amplification circuit is used. The MCU output operates the mosfet switch, which in turn modulates the transducer driving signal from the DC to DC converter. Finally, a $3 \mathrm{~V}$ power supply is used to power the circuit. For much of the testing, the power source was a DAQ, as shown later in the bench top setup, but a $3 \mathrm{~V}, 24 \mathrm{~mm}$ coin cell battery was used during testing on the hydrokinetic machine.

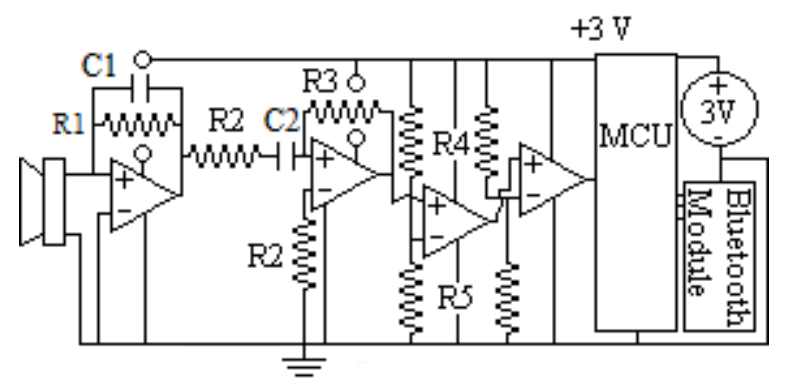

R1:2.2 kOhm R3:1 MOhm R5: $23.2 \mathrm{kOhm} \mathrm{C2:0.0033} \mathrm{uF}$ $\mathrm{R} 2: 1.5 \mathrm{kOhm} \mathrm{R} 4: 9.6 \mathrm{kOhm} \mathrm{C1:10} \mathrm{pF}$

Figure 15: Receiver Circuit 
The major tasks for the receiver circuit are to receive the acoustic signal, process it, and retransmit wirelessly through air (Bluetooth in this case). An ultrasonic transducer receives the transmitted acoustic signal. This signal is then conditioned to make it more easily 'readable' by the MCU. First, the signal passes through a charge amplifier which converts the charge developed across the piezoelectric transducer into a voltage proportional to the gain of the amplifier. The signal is then passed through an active high pass filter with a cutoff frequency of approximately $32 \mathrm{kHz}$ and a gain value of 667, thus filtering and further amplifying the received signal. The filtering process allows the required $40 \mathrm{kHz}$ signal through while removing anticipated background noise that would be found in a river, such as rain, wind, and fish acoustics. After being filtered and amplified, the signal is then modified by two comparators in sequence. The comparators convert the roughly sinusoidal signal into a clean square wave pulse train, which is easier for the MCU to process.

\section{b. Acoustic Transmission Frequency}

A $40 \mathrm{kHz}$ acoustic signal was selected based on three main considerations. First, ambient noise sources encountered in the hydrokinetic energy system environment, both natural and artificial, were considered. Second, we considered the audibility of the signal to humans. Finally, the relationship between attenuation rate and data transmission rate at acoustic frequencies was considered.

Two natural sources and two artificial sources of ambient noise are likely to be encountered underwater in a river. The two natural sources are wind and rain noise, while the artificial noise sources originate from boat motors and ultrasonic range/fish finders. Both wind and rain have distinct acoustic power spectrums ${ }^{19}$. Wind noise can be approximated using Knudsen curves, which show that at about 500 to $1000 \mathrm{~Hz}$, the magnitude of wind noise decreases with increasing frequency. While the wind noise does not disappear entirely in the ultrasonic region, it is severely reduced in strength and is not considered a significant noise source. Rain has a distinct peak in strength at around 14 to $16 \mathrm{kHz}^{19}$, and then also decreases in strength with increasing frequency. However, rain has been shown to suppress wind noise, and its peak is closer to the ultrasonic range. As such, of the two natural sound sources rain is the more concerning. For artificial noise sources, motor boat noise does not exceed $1 \mathrm{kHz}^{20}$, and therefore is not a concern for the ultrasonic frequencies used here. However, the commercial sonar products that many boats are equipped with are a concern, as they rely on producing ultrasonic pings to visualize the underwater environment. The frequency for commercial sonar applications ranges from $20 \mathrm{kHz}$ to $400 \mathrm{kHz}$ generally, and the most common frequencies used are $50 \mathrm{kHz}$ and $200 \mathrm{kHz}$. Therefore selecting an ultrasonic communication frequency away from 50 or $200 \mathrm{kHz}$ is best for mitigating interference from such ultrasonic devices.

The second criterion we evaluated was the audibility of the communication signal to humans. Specifically, we require the operating frequency to be inaudible to the human ear. This criterion is selected to reduce noise pollution that would potentially be generated by the system operation, and as such it is highly desirable that the signal produced be inaudible to both humans and many aquatic river organisms. The selection of an ultrasonic frequency is an easy way to alleviate this concern, as humans cannot hear in the ultrasonic range and many fish species can only hear in a range of 20 to $300 \mathrm{~Hz}^{20}$. 
The third criterion considered was signal attenuation and transmission rate in an underwater environment. In acoustic communication in water, the rate of attenuation and maximum data transmission rate are directly linked. More specifically, as frequency increases both the attenuation rate and the data transmission rate increase. Thus, a very low frequency signal can travel very large distances in water, but has a very slow rate of data transmission, whereas a high frequency ultrasonic signal travels shorter distances, but has higher data transmission rate. The attenuation of acoustic waves in seawater is shown in FIG.5 and is given by Ainslie and $\mathrm{McColm}^{21}$ as

$$
\alpha=0.00049 f^{2} \exp (-(T / 27+D / 17))
$$

where $f$ is the frequency in $\mathrm{kHz}, T$ is temperature in degrees Celsius, and $D$ is depth underwater in kilometers. Figure 16 assumes a temperature of $22^{\circ} \mathrm{C}$ and depth of $1 \mathrm{~m}$.

The transmission rate is simply the frequency of the waveform divided by the number of periods that are used to represent one bit of data. The system described here uses 5 periods of the 40 $\mathrm{kHz}$ waveform to represent one bit and the resulting transmission rate is shown in FIG.5. Since having both low attenuation rate and a high data transmission rate are mutually exclusive, the operating frequency for the system must be selected for the systems' requirements.

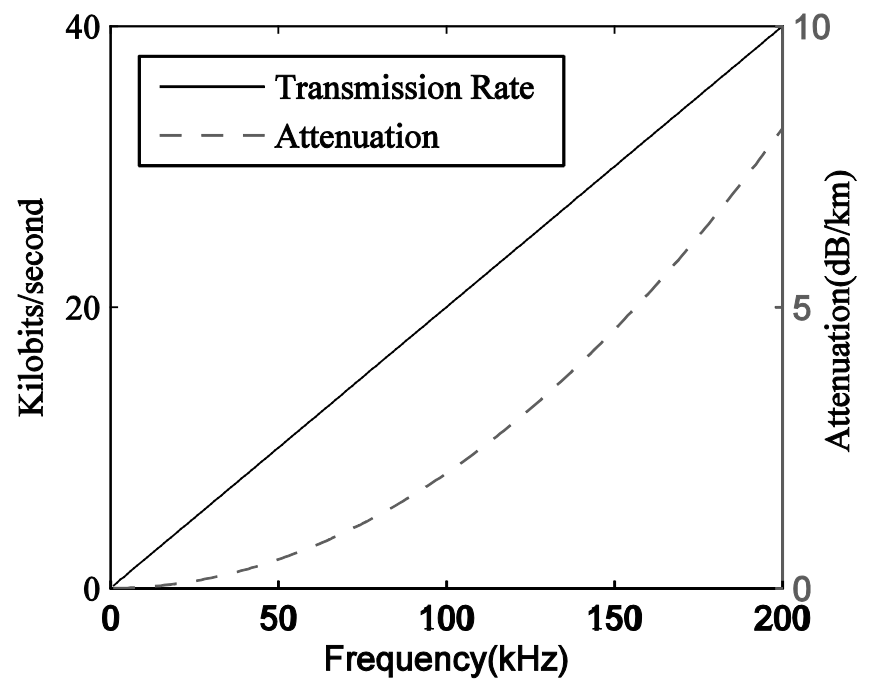

Figure 16: Attenuation and transmission rate of transmitter circuit vs. frequency in sea-water $\left(22^{\circ} \mathrm{C}\right)$ at depths of $1 \mathrm{~m}$.

Based on these factors, we selected a $40 \mathrm{kHz}$ signal. This ultrasonic frequency is not near either 50 or $200 \mathrm{kHz}$, and therefore alleviates both natural and artificial noise concerns. Because 40 $\mathrm{kHz}$ is in the ultrasonic frequency range it is inaudible to humans and most aquatic animals. Finally, $40 \mathrm{kHz}$ has low attenuation rate on the order of $0.5 \mathrm{~dB} / \mathrm{km}$ and relatively high $8 \mathrm{kbits} / \mathrm{sec}$ rate of data transfer. While higher frequency and the resulting higher data transfer rate would increase the "real-time" nature of the transmission, for this proof-of-concept system we place more emphasis on low attenuation so as to maintain a high signal-to-noise ratio and maintain reliable communication. 


\section{c. Data Encoding}

The software running on the two MCUs encodes the structural health data for underwater transmission from the rotating blade and then decodes the data once received at the static relay station. In order to transmit the acquired data (simulated here as a voltage signal between 0-10 $\mathrm{V}$ ), the transmitter MCU encodes the data before it is sent. This encoding for transmission is a modified on-off keying (OOK) encoding scheme, where a ' 1 ' data bit is indicated with 5 periods of the $40 \mathrm{kHz}$ sine wave and a ' 0 ' data bit is indicated with a period of silence that lasts the equivalent time of 5 periods of the $40 \mathrm{kHz}$ sine wave (i.e., $125 \mu \mathrm{s}$ ). Figure 17 illustrates the encoding scheme. We have modified the standard OOK encoding by including four clock train ' 1 ' bits at the beginning of the data transmission sequence and also padding the space between each clock-train bit in the transmission with a period of silence. This modification eliminates the effect of echo encountered in the underwater environment. An example of a transmitted ' 1 ' data bit and the subsequent echo is shown in Figure 18. The four clock bits allow the receiving circuit to synchronize with the transmitting circuit, thus preventing the receiving circuit from triggering on an erroneous echo signal. In effect the initial clock train of data provides an initial condition from which the receiving circuit can synchronize the remainder of the transmitted data. In this way the transmission and reception circuits are synchronized and the 10-bit structural health data are transmitted from the rotating blade to the static relay station.

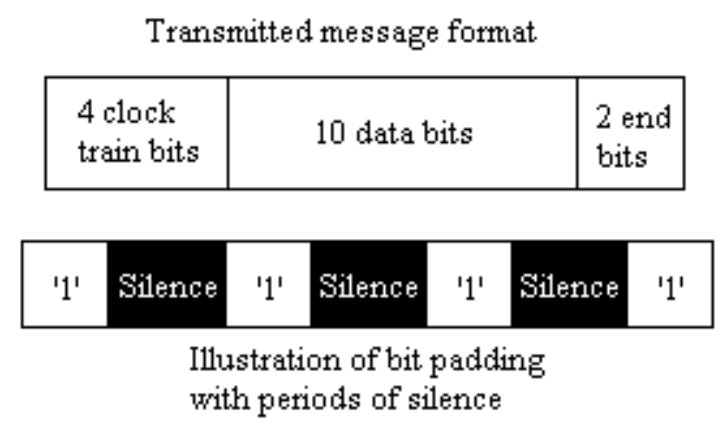

Figure 17: Signal encoding scheme. 


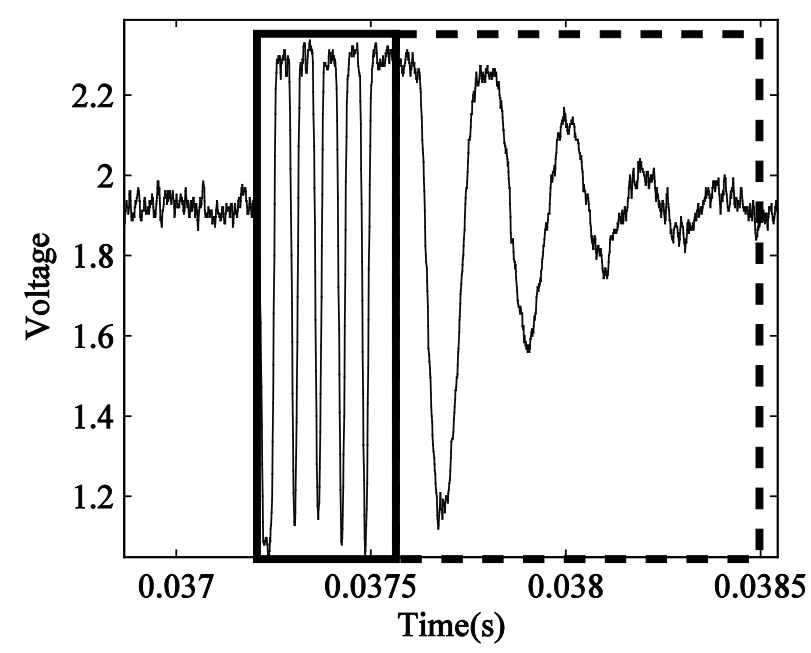

\section{Figure 18: Transmitted ' 1 ' bit (solid box) and the following echo (dashed box)}

The MCU of the receiver circuit listens for and receives transmissions, determines if the transmission is valid, decodes the transmission, and then rebroadcasts the data via Bluetooth. Since the receiving circuit is not in the rotary frame of reference, it can be powered directly from the turbine (or wall during lab testing) and therefore does not spend time sleeping like the transmitter. Instead it spends most of its time listening for an incoming transmission. Upon initial detection of a $40 \mathrm{kHz}$ signal, the MCU determines if the signal is the 4-bit clock-train indicating initiation of data transmission by listening for the four ' 1 ' bits with silence in between (as illustrated in Figure 17). The MCU then times the duration between each of the clock bits, and takes the average time of the periods of silence between them. In this way the MCU synchronizes with the transmitter. The next 10 data bits are then received as well as the two stop bits, which serve to indicate that the message has been successfully transmitted. If both stop bits are not received, the MCU rejects the data as not being a valid communication. In the case of correct transmission, the 10 data bits are converted back to a positive integer value and saved for retransmission via the Bluetooth. Once all the data packets from the transmitter have been received and saved, the saved data are then transmitted from the MCU to the attached Bluetooth module, which then relays the data wirelessly to a remote monitoring station. Following Bluetooth transmission, the receiver MCU returns to listening for the next communication.

\section{d. Static Bench Top Testing}

The electronics and software were tested to validate correct operation and to characterize the power use of the system. For these experiments a static bench top setup was used. For this setup only the acoustic transducers were placed in water, the other electronics are dry, and all components are statically mounted, i.e., there is no rotating turbine blade reference frame, only the lab frame. A photograph of the setup is shown in Figure 19. In the figure, a NI USB-6008 DAQ (1) simulates a coin cell battery by providing a constant $3 \mathrm{~V}$ power supply to the various electric components. A Sparkfun BlueSMiRF Silver chip (2) is the Bluetooth transmitter connected to the receiver circuit (3). Both the receiver and transmitter circuits (4) are connected to an ultrasonic transducer in the aquatic environment (5). Finally, a Tektronix TDS-2014B oscilloscope (6) was used to measure voltage input and output from the various electric circuit 
components. To characterize the power of the transmitter circuit, the required current and time duration of the different modes of the MCU were measured. For the current measurement, a $3 \mathrm{~V}$ coin cell battery was used instead of the DAQ to insure the accuracy of the measurements. The current was measured with a Fluke multi-meter in series with the battery and circuit, while the time duration for each mode was measured with the oscilloscope.

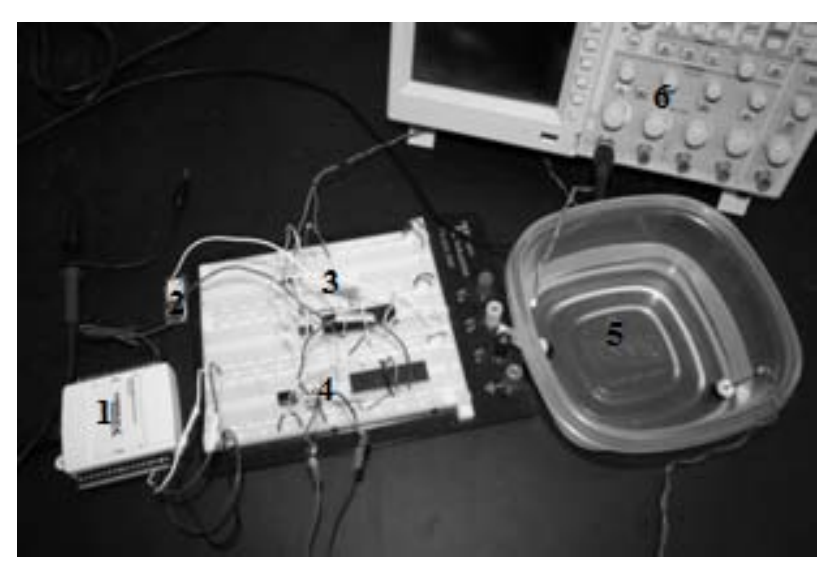

\section{Figure 19: Bench top setup for communication validation and power consumption investigation.}

\section{e. Dynamic Hydrokinetic Testing Platform}

The data transmission system was also tested on a hydrokinetic turbine in a water tunnel in order to better replicate the real world operating environment. A numerical investigation of this machine is presented in Ref. 22. The water tunnel is capable of laminar flow up to $1 \mathrm{~m} / \mathrm{s}$ (1.9 kts) and has a test section cross-section of $38.1 \times 50.8 \mathrm{~cm}$ and length of $152.4 \mathrm{~cm}$. For tests presented here, the water flow speed was $0.25 \mathrm{~m} / \mathrm{s}$ and the hydrokinetic turbine had a rotational speed of around $42 \mathrm{rpm}$. The hydrokinetic turbine has a shaft diameter of $0.94 \mathrm{~cm}$ and is made of aluminum. The turbine has three constant chord blades that are made of aluminum with a blade width of $1.27 \mathrm{~cm}$ and blade length of $12.7 \mathrm{~cm}$.

The data transmission system was mounted to the hydrokinetic machine and water tunnel as shown in Figure 20. The receiver circuit was mounted on top of the tunnel (dry), with the receiving transducer located in the water and approximately $7.5 \mathrm{~cm}$ directly upstream of the transmitter along the centerline axis of the turbine shaft. The receiving transducer was oriented to collect acoustic signals travelling in the upstream direction from the hub. The transmitting circuitry and transducer were attached to the rotating frame of the hydrokinetic machine underwater. The transducer was mounted to the nose of the turbine hub on the centerline axis of the shaft and oriented to transmit data in the upstream direction. The transmitter circuitry was encased in a waterproof container attached to the turbine shaft. 


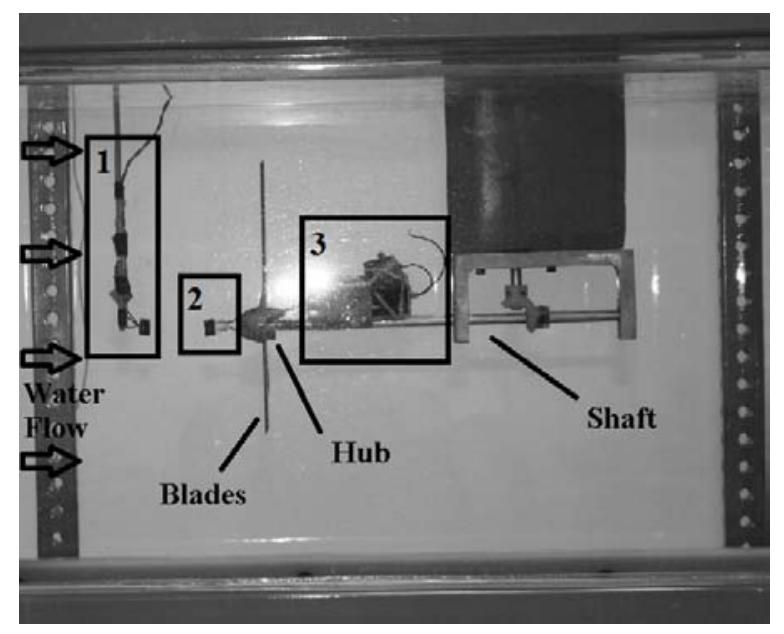

\section{Figure 20: Water Tunnel Test Section with (1) Receiver Transducer, (2) Transmitting Transducer, and (3) Power and Electronics Module.}

\section{Results and Discussion}

The structural health data transmission process described above was first tested in a static environment, and then it was demonstrated on a hydrokinetic turbine in a dynamic water tunnel. First we describe the initial validation process that demonstrates accurate transmission of simulated structural health data from the blade to the remote monitoring station. This process is demonstrated for multiple simulated health data signals. Then we analyze the power requirements of the system and investigate the effect of operation mode on transmitter power supply lifetime. Finally, we demonstrate the technique in a dynamic environment by attaching the data communication system to a prototype hydrokinetic turbine in a water tunnel.

\section{a. Data Transmission Validation}

To demonstrate and validate the data communication process, several different health data waveforms were communicated. These different waveforms simulate possible outputs from the embedded fiber optic strain gauge. Initially the error associated with the ADC of the MCU is quantified, along with the precision of the measurement electronics. Then data from the transmitted waveforms is presented, which include a constant value, a square wave, and one halfcycle of a sine wave. For the results presented below, the communication system is tested in a static benchtop environment.

The ADC of the MCU has a resolution of 10 bits. This corresponds to 1023 separate voltage values that can be measured in the range from $0 \mathrm{~V}$ to the saturation voltage of the ADC, which is either $5 \mathrm{~V}$ or the voltage supplied to the MCU. In this case, the MCU supply voltage is $3 \mathrm{~V}$, meaning that the theoretical precision of the ADC is $2.9 \mathrm{mV}$. To experimentally determine the accuracy of the ADC and associated transmission circuitry, we applied known voltages to the voltage divider and measured the resulting received signal from the monitoring station. Specifically, voltages from 3.0 to $1.2 \mathrm{~V}$ were applied with a resulting experimentally determined error of $\pm 5 \%$. So the 10 -bit resolution provides a precision of $2.9 \mathrm{mV}$ with an error in the reported data of $\pm 5 \%$. 
Received data for the constant value and square wave waveforms are shown in Figure 21. For the constant value data transmission, a voltage of $0.499 \pm 0.005 \mathrm{~V}$ was input into the transmitter circuit. As Figure 21 shows, the remote monitoring station received 50 data points over a time period of 6.2 seconds, all of which have a value of $0.495 \pm 0.025$ V. For the square wave, the period of the wave was chosen as 10 data samples with a min and max voltage of $0.367 \pm 0.005 \mathrm{~V}$ and $0.733 \pm 0.005 \mathrm{~V}$, respectively. The waveform was connected to the transmitter circuit and the remote monitoring station received the signal shown in Figure 21, with all output voltages within $\pm 5 \%$ of the input.

Results from the half-cycle of a sine wave data transmission are shown in Figure 22, along with the input signal. A slowly varying $0.08 \mathrm{~Hz}$ sine wave with an amplitude of $4.70 \pm 0.01 \mathrm{~V}$ was the input. Over the 6.2 second long half-cycle, the communication system transmitted 50 data points corresponding to discretized points of the sine wave. The received data are within the previously measured $\pm 5 \%$ of the measured input voltage.

Finally, we assessed the fraction of transmitted data points that result in an error output from the receiver circuit, and we call this the data error fraction. The system was setup to act as it would in actual operation, transmitting a set of data(simulated in this case), sleeping, then transmitting more data. Over the course of four iterations of this procedure, consisting of 4400 data points, we found that $0.1 \%$ of the transmitted data points were in error.

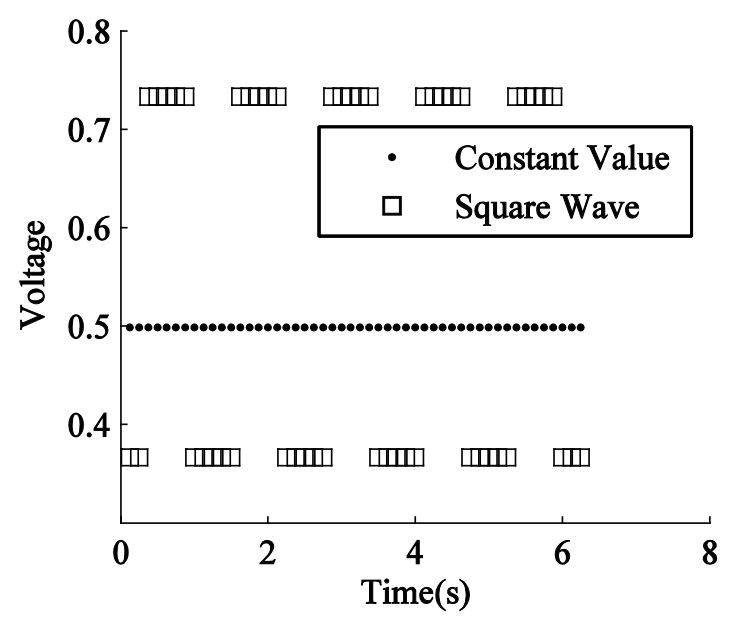

Figure 21: Constant and square wave simulated structural health data transmitted to the remote monitoring station. 


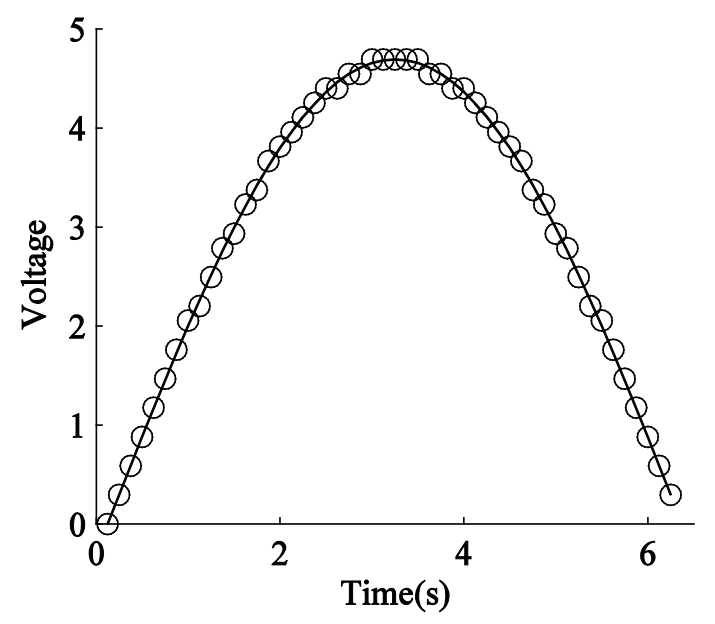

\section{Figure 22: Half-cycle sine wave simulated structural health data transmitted to the remote monitoring station.}

\section{b. Testing on a Dynamic Hydrokinetic Energy Platform}

The data transmission system was setup and operated on a dynamic hydrokinetic energy platform as described above. Transmitter circuitry and transducer were attached to the rotating reference frame of the blade, while the receiver was positioned directly upstream in the water. Received data were transmitted wirelessly via Bluetooth to the remote monitoring station. The transmitter circuit was pre-programmed to output the constant, square wave, and sinusoid data, exactly the same as shown in Figure 21 and Figure 22.

Data received by the remote monitoring station during dynamic testing on the hydrokinetic machine appeared similar to that shown in Figure 21 and Figure 22. This result indicates that the data transmission system can be operated in a relevant environment and within the rotating reference frame of the hydrokinetic blades. However, initially we find that more of the transmitted data results in an error from the receiver circuitry. While the benchtop setup had a data error fraction of $0.1 \%$, we find that when testing on the hydrokinetic machine about $2 \%$ of the data points result in an error output from the receiver.

The increase in data error fraction during the initial test is due to the larger aquatic environment and the resulting increase in expansion and attenuation of the acoustic signal. We modified the setup shown in Figure 20 by placing a 7.62-cm-diameter by $11.43-\mathrm{cm}$-long cylinder between the transmitting and receiving transducers. The cylinder was attached to the receiver and was therefore statically mounted (not rotating). The cylinder reduces the expansion and attenuation of the acoustic signal by guiding the acoustic waves from the transmitter to the receiver. With this modified setup, we find that only $0.9 \%$ of the data result in an error output.

\section{c. Power Analysis}

The power requirements of the transmitter circuit were investigated in order to assess and predict the operational lifetime of the communication system. We envision the transmitter circuit embedded into the hub of the turbine shaft and battery powered within the rotating reference frame of the turbine. While other power options are available, including energy harvesting and a 
shaft-mounted power take-off, the following analysis assumes the transmitter is operated with a battery of known capacity. The receiver circuit is statically located and can be fed power directly from the generator, so its power consumption is not limited and not investigated here.

Power consumption is calculated using the measured voltage and current output by the battery of the transmitter circuit. In this case, the battery is outputting a constant $3 \mathrm{~V}$ signal. The static bench top setup was used with the exception that the battery was used to power the transmitter circuit. Current drawn from the battery was measured for the three possible modes of transmitter circuit operation: sleep, sampling, and transmission. The time the transmitter spends in each of these modes is also measured. These results are given in Table 8 . The ' $X$ ' used in Table 8 is the duty cycle, the ratio of time spent 'asleep' to time 'awake'. A plot of the current consumption of the transmitter as a function of duty cycle is shown in Figure 23.

Table 8: Transmitter current during different operating modes ( $3 \mathrm{~V}$ battery supply)

\begin{tabular}{lccc}
\hline \hline \multicolumn{1}{c}{ Mode } & $\begin{array}{c}\text { Time } \\
(\mathbf{m s})\end{array}$ & $\begin{array}{c}\text { Current } \\
(\mathbf{m A})\end{array}$ & $\begin{array}{c}\text { Current*Time } \\
\left(\mathbf{m A}^{*} \mathbf{m s}\right)\end{array}$ \\
\hline Sleep & $160.1 \mathrm{X}$ & 0.03 & $4.80 \mathrm{X}$ \\
ADC & & & \\
sampling & 0.1 & 2.31 & 0.23 \\
Transmission & 160 & 10.01 & 1601.6 \\
\hline \hline
\end{tabular}

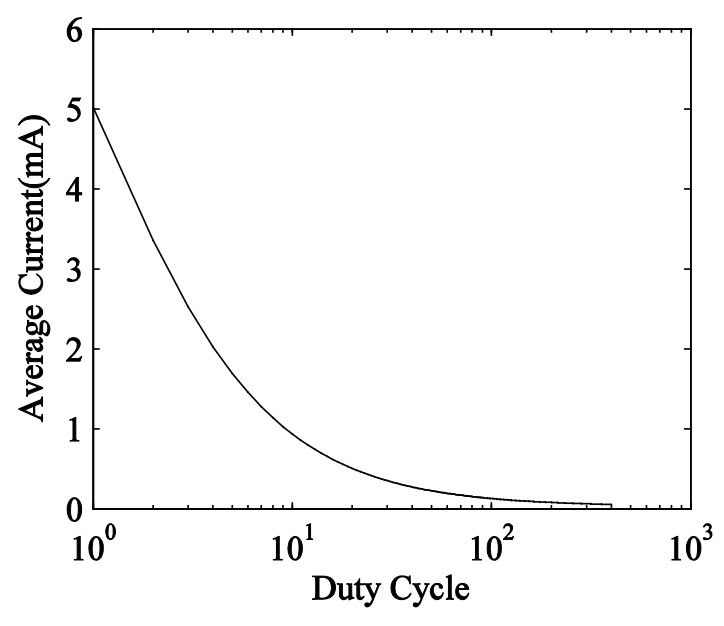

Figure 23: Time averaged current draw of the transmitter circuit vs. duty cycle

The maximium operational duration of the transmitter can be estimated using the average current data and known battery capacity. Battery capacity (measured in mA-hr) is divided by the average current, yielding the maximum time in hours that the battery can source the required current. Using the average current results from Figure 23, the maximum operational lifetime of the transmitter circuit is plotted in Figure 24 for batteries with different capacity. The battery capacities shown in Figure 24 are typical of commercial off-the-shelf coin cell batteries. Table 9 highlights the duty cycle required to achieve a desired duration of operation, along with the time the transmitter spends sleeping for that duty cycle. For example, to power the transmitter for 1 
year using a $560 \mathrm{~mA}$-hr coin cell battery requires a duty cycle of 294, which means data will be acquired and transmitted about every 47 seconds for the entire year.

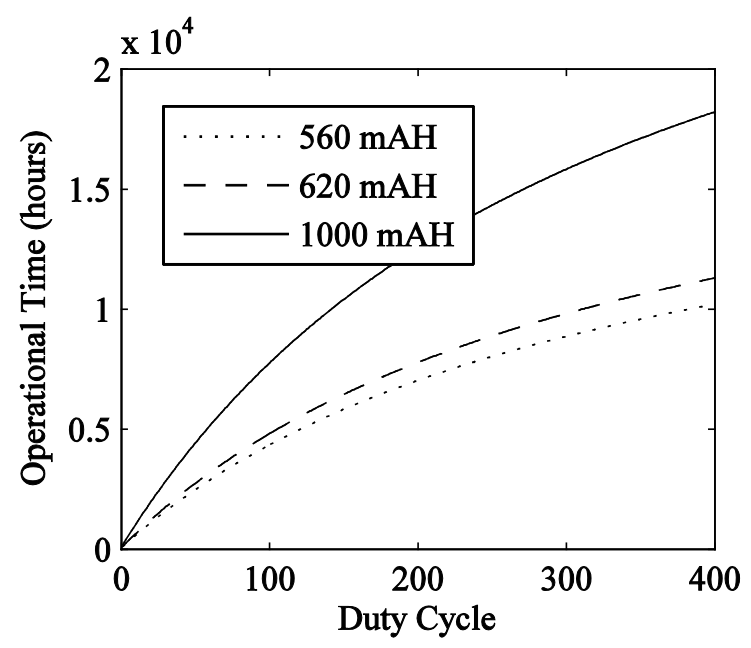

Figure 24: Predicted transmitter circuit operating time vs. duty cycle for different battery capacity

Table 9: Duty cycle and sleep duration for a desired transmitter circuit operating time for various battery capacities

\begin{tabular}{c|ccc}
\hline \hline & \multicolumn{3}{|c}{ Duty Cycle ('Sleep' Time (sec)) } \\
Operating & $\mathbf{5 6 0} \mathbf{m A -}$ & $\mathbf{6 2 0} \mathbf{m A -}$ & $\mathbf{1 0 0 0} \mathbf{~ m A -}$ \\
Time & hr & hr & hr \\
\hline 1 week & $3(0.48)$ & $2(0.32)$ & $2(0.32)$ \\
2 weeks & $6(0.96)$ & $5(0.80)$ & $3(0.48)$ \\
1 month & $12(1.92)$ & $11(1.76)$ & $6(0.96)$ \\
1/2 year & 91 & 80 & $45(7.20)$ \\
& $(14.57)$ & $(12.81)$ & \\
1 year & 294 & 244 & 118 \\
& $(47.07)$ & $(39.06)$ & $(18.89)$ \\
2 years & 5080 & 1851 & 368 \\
& $(813)$ & $(296)$ & $(58.92)$ \\
\hline \hline
\end{tabular}

The ability to remotely monitor the structural health of hydrokinetic turbine blades is of interest for two main applications. First, structural health data can provide service and maintenance personnel with much needed knowledge of the state of the blades, allowing timely repair and servicing before failure. Second, health data can aid environmental assessment studies of prototype machines, providing information on both the impact of the machine on the environment and the environment on the machine. In both cases, the investigated system will ideally enable faster future commercial deployment of hydrokinetic energy systems. 
Results indicate that the data transmission system should be operated in different modes depending on the desired application. Specifically, the transmitter circuit should be operated with a duty cycle suited for the duration of the application. To achieve longer operational duration of the transmitter, a higher duty cycle is required. We anticipate that commercially deployed hydrokinetic machines will require long operational duration and thus high duty cycle, while shorter-term environment assessment studies will benefit from lower duty cycle operation. For example, environmental assessment testing of a prototype machine is a relatively short timeline on the order of days or weeks compared with a commerically deployed device that will be in water for years. Fast detection of changes in structural health are typically required for environment assessment (i.e., immediate detection of an impact), while more intermittent assessment of structural health can be tolerated with long-term commercial machines. Therefore, for short duration environmental assessment continuous max sampling should be used, providing a sample rate of 500 samples/sec. A $1000 \mathrm{~mA}$-hr battery would last at most around 4 days at this rate. For a two-year deployment of a commercial system with a $1000 \mathrm{~mA}$-hr battery, the transmission system should be operated with at least a duty cycle of 368 to provide a data sample about every 59 seconds.

\section{Accomplishments}

The project accomplished all objectives by demonstrating embedding fiber optic strain gages and underwater acoustic communication of simulated strain data. These results were presented at international conferences and results in the publications described in Refs. 29, 30, and 31.

\section{Conclusions}

Strain characteristics of composite beams and blades were investigated. A composite blade was successfully fabricated and instrumented. Samples were experimentally and theoretically analyzed for static and dynamic strain characteristics. The strain results from experiment behavior and the theoretical analysis generally matched. The test cases measured static flexural strain and the free-vibration dynamic response. All samples were undamaged, but these results will be compared to that of otherwise-identical damaged blades in future work. The application area is hydrokinetic turbine technology. This work is a preliminary step to understanding the strain behavior of composite blades for rotating turbine applications. The immediate goal is to understand the strain signature for normal cyclic operation and for impact events. Changes in this signature need to be linked to structural health. The long-term goal is to assess the feasibility of a health monitoring approach.

Further development of this health monitoring approach for turbine blades requires a full characterization of blade behavior and advances in sensing, instrumentation, and data acquisition. The composite blade behavior, for undamaged and damaged cases, must be experimental and theoretical verified for dynamic loading that is representative of typical hydrokinetic operation, e.g. operation in water and under cyclic loading. The strain characterization will give a tool for evaluating blade design and will give insight toward the needed processing for the strain signal processing. For instance, what are the features in a strain signature that are closely linked to common damage and what intelligent processing is needed to highlight these features? Fiber optic sensors need to be incorporated in turbine blades and the blade performance needs to be characterized for expected damage mechanisms. Embedded 
instrumentation must be tailored for demodulation of the sensor signals and must be incorporated into the blade hub. The embedded instrumentation must be integrated with the ultrasonic transmitter.

The data transmission system can successfully communicate representative structural health data in a benchtop setting and also from the rotating reference frame of a prototype hydrokinetic energy system. Data can be transmitted acoustically underwater from an isolated source (transmitter, blade reference frame) to a static relay station (receiver, fixed reference frame), and then broadcast wirelessly to a remote monitoring station (via Bluetooth). Error in the electronics measuring the structural health signal limit the accuracy of the measurements to $\pm 5 \%$. Results from testing on a prototype hydrokinetic machine indicate that the ultrasonic and Bluetooth communication can transmit 10 bit data with an error fraction of only $0.9 \%$ when the acoustic signal is properly guided from the transmitter to receiver. If the acoustic signal is allowed to expand using the current acoustic transducers and signal power level, the data error fraction increases to $2 \%$.

The maximum rate at which the structural health data can be transmitted is 500 samples/sec. Each sample of structural health data is captured by the measurement electronics with 10 bit resolution, and the entire 10 bit data packet is transmitted. With our modified on-off keying encoding scheme, the underwater acoustic communication system must transmit a total of 16 bits: 10 data bits, 4 clock train bits, and 2 termination bits. With the $40 \mathrm{kHz}$ acoustic frequency, each bit requires $0.125 \mathrm{~ms}$, resulting in a total transmission time for 1 data sample of $2 \mathrm{~ms}$. Thus, assuming continuous data transmission, a maximum rate of 500 samples per second can be achieved by the data transmission system.

The optimum mode of operation of the data transmission system is dependent on the hydrokinetic machine application. We examined application of the data transmission system to short term environmental impact testing of prototype hydrokinetic machines and long term commercially-deployed machines. For prototype testing, the desired goal of the data transmission system is to precisely record in real time the structural health and blade loading experienced under various conditions. This could include detailed strain response of the system over time, the response to impact or other transient events, and monitoring the evolution of the degradation and damage the blades experience. For prototype testing the data transmission system should operate at maximum sampling rate. Based on our analysis, max sampling rate could be achieved for 50+ hours of testing with any of the battery power sources described.

A commercially-deployed hydrokinetic system requires a longer lifetime than a prototype system. In this case, the data transmission system should make periodic structural health measurements, transmit the data, and then enter sleep mode to conserve power. While this mode of operation does not allow for "real-time" transient events to be monitored, it does extend the life of the monitoring system while still detecting deterioration and damage to the hydrokinetic blade. Based on our results, a data transmission system lifetime of two years can be achieved by increasing the duty cycle (sleep time) of the system. Using a relatively low capacity $560 \mathrm{~mA}-\mathrm{hr}$ battery, a duty cycle of 5080 would provide operation for two years, and would measure the structural health data every 13 minutes 33 seconds throughout the 2 year period. If higher sampling rate is desired, a $1000 \mathrm{~mA}$-hr battery could be used at a duty cycle of 368, which would acquire and transmit data every 59 seconds. Based on the capacity of the battery and duty cycle 
(sleep time) of the system, intermittent monitoring can be achieved for relatively long periods of time.

\section{References}

${ }^{1}$ Akyildiz, I. F., Pompili, D., Melodia, T., "Underwater acoustic sensor networks: research challenges," Ad Hoc Networks, Vol. 3, pp. 257-279, 2005.

${ }^{2}$ Khan, M. J., Bhuyan, G., Iqbal, M. T., Quaicoe, J. E., "Hydrokinetic energy conversion systems and assessment of horizontal and vertical axis turbines for river and tidal applications: A technology status review," Applied Energy, Vol. 86, pp. 1823-1835, 2009.

${ }^{3}$ Khan, M. J., Iqbal, M. T., Quaicoe, J. E., "River current energy conversion systems: Progress, prospects and challenges," Renewable and Sustainable Energy Reviews, Vol. 12, pp. 2177-2193, 2008.

4"Proceedings of the Hydrokinetic and Wave Energy Technologies Technical and Environmental Issues Workshop," S. S. Schwartz, ed., Prepared by RESOLVE, Inc., Washington, D.C., 2006.

5"FERC Hydrokinetic Projects," http://www.ferc.gov/industries/hydropower/geninfo/licensing/hydrokinetics.asp, 2010.

${ }^{6}$ Asmus, P., Wheelock, C., "Hydrokinetic and Ocean Energy: Renewable Power Generation from Ocean Wave, Tidal Stream, River Hydrokinetic, Ocean Current, and Ocean Thermal Technologies," Market Research Report, Pike Research, 2009.

7"Pelamis Wave Power Website," http://www.pelamiswave.com/, 2010.

8 "Ocean Power Technologies Web Page," http://www.oceanpowertechnologies.com/index.htm, 2010.

9"Voith Hydro Wavegen Limited Website," http://www.wavegen.co.uk/index.html, 2010.

10"Open Hydro Webpage," http://www.openhydro.com/home.html, 2010.

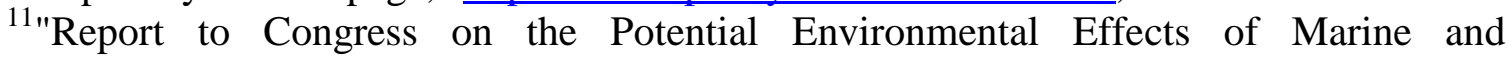
Hydrokinetic Energy Technologies," U.S. Dept. of Energy, Dec. 2009.

${ }^{12}$ Sale, M. J., Cada, G. F., Acker, T. L., Carlson, T., Dauble, D. D., Hall, D. G., "DOE Hydropower Program Biennial Report for FY 2005-2006," ORNL/TM-2006/97, U.S. Dept. of Energy, July 2006.

${ }^{13}$ Cada, G., Ahlgrimm, J., Bahleda, M., Bigford, T., Stavrakas, S. D., Hall, D., Moursund, R., Sale, M., "Potential Impacts of Hydrokinetic and Wave energy Conversion Technologies on Aquatic environments," Fisheries, Vol. 32, No. 4, pp. 174-181, April 2007.

${ }^{14}$ Coutant, C. C., Cada., G. F., "What's the future of instream hydro?," Hydro Review XXIV, Vol. 6, pp. 42-49, 2005.

${ }^{15}$ Previsic, M., "System Level Design, Performance, Cost and Economic Assessment Alaska River In-Stream Power Plants," EPRI RP 006 Alaska Electric Power Research Institute, Oct. 31, 2008.

16"Hydrokinetic Electric Power Generation," Climate TechBook, Pew Center on Global Climate Change, Dec. 2009.

${ }^{17}$ Walford, C. A., "Wind Turbine Reliability: Understanding and Minimizing Wind Turbine Operation and Maintenance Costs," Sandia Report SAND2006-1100, Prepared by Global Energy Concepts, LLC, Mar. 2006.

${ }^{18}$ Ricci, R. P., Morichelli, L., Santini, M., "Remote control of implanted devices through Home Monitoring technology improves detection and clinical management of atrial fibrillation," EP-Europace, Vol. 11, pp. 54-61, 2009. 
${ }^{19}$ Fasasi, T., Maynard, D., Nasr, H., Patwari, R., Mashetti, S., "Wireless sensors remotely monitor wells in Nigeria swamps," Oil \& Gas Journal, May 9, 2005.

${ }^{20}$ Ciang, C. C., Lee, J.-R., Bang, H.-J., "Structural health monitoring for a wind turbine system: a review of damage detection methods," Measurement Science and Technology, Vol. 19, pp. 122001, 2008.

${ }^{21}$ Dutton, A. G., Blanch, M. J., Vionis, P., Lekou, D., Delft, D. R. V. v., Joosse, P. A., Anastassopoulos, A., Kouroussis, D., Kossivas, T., Philippidis, T. P., Assimakopoulou, T. T., Fernando, G., Doyle, C., Proust, A., "Acoustic Emission Condition Monitoring of Wind Turbine Rotor Blades: Laboratory Certification Testing to Large Scale In-Service Deployment," European Wind Energy Conference - EWEC, Madrid, Spain, 2003.

${ }^{22}$ M.J.Blanch, A.G.Dutton, "Acoustic Emission Monitoring of Field Tests of an operating Wind Turbine," Key Engineering Materials, Vol. 245-246, pp. 475-482, July 2003.

${ }^{23}$ Takeda, N., "Characterization of microscopic damage in composite laminates and realtime monitoring by embedded optical fiber sensors," International Journal of Fatigue, Vol. 24, pp. 281-289,

${ }^{24}$ Akhavan, F., Watkins, S. E., Chandrashekhara, K., "Measurement and analysis of impact-induced strain using extrinsic Fabry-Perot fiber optic sensors," Smart Material Structures, Vol. 7, pp. 745-751, 1998.

${ }^{25}$ EWatkins, S., Akhavan, F., Dua, R., Chandrashekhara, K., Wunsch, D. C., "Impactinduced damage characterization of composite plates using neural networks," Smart Material Structures, Vol. 16, pp. 515-524, 2007.

${ }^{26}$ Wills, J., Ye, W., Heidemann, J., "Low Power Acoustic Modem for Dense Underwater Sensor Networks," 1st ACM International Workshop, New Orleans, LA, May 18, 2009.

${ }^{27}$ Sherman, C. H., Butler, J. L., Transducers and Arrays for Underwater Sound, Monograph Series in Underwater Acoustics, R. R. Goodman, H. P. Bucker, I. Dyer, and J. A. Simmen, ed., Springer, New York, NY, 2007.

${ }^{28}$ Moore, J. H., Davis, C. C., Coplan, M. A., Building Scientific Apparatus: A Practical Guide to Design and Construction, Perseus Books, Cambridge, MA, 2003.

${ }^{29}$ Heckman, A. J., Rovey, J. L., Chandrashekhara, K., Watkins, S. E., Mishra, R., Stutts, S., "Ultrasonic Underwater transmission of Composite Turbine Blade Structural Health," Paper 8343-23, SPIE Smart Structures and Materials, Non-destructive Evaluation, and Health Monitoring Conference, San Diego, CA, Mar. 11-15, 2012.

${ }^{30}$ Robison, K., Watkins, S. E., Nicholas, J., Chandrashekhara, K., Rovey, J. L., "Instrumented Composite Turbine Blade for Health Monitoring," Paper 8347-93, SPIE Smart Structures and Materials, Non-destructive Evaluation, and Health Monitoring Conference, San Diego, CA, Mar. 11-15, 2012.

${ }^{31}$ Heckman, A. J., Rovey, J. L., Chandrashekhara, K., watkins, S., Stutts, D., Banerjee, A., Mishra, R., "Structural Health Monitoring Data Transmission for Composite Hydrokinetic Turbine Blades," Journal of Renewable and Sustainable Energy, in review 6/2012. 